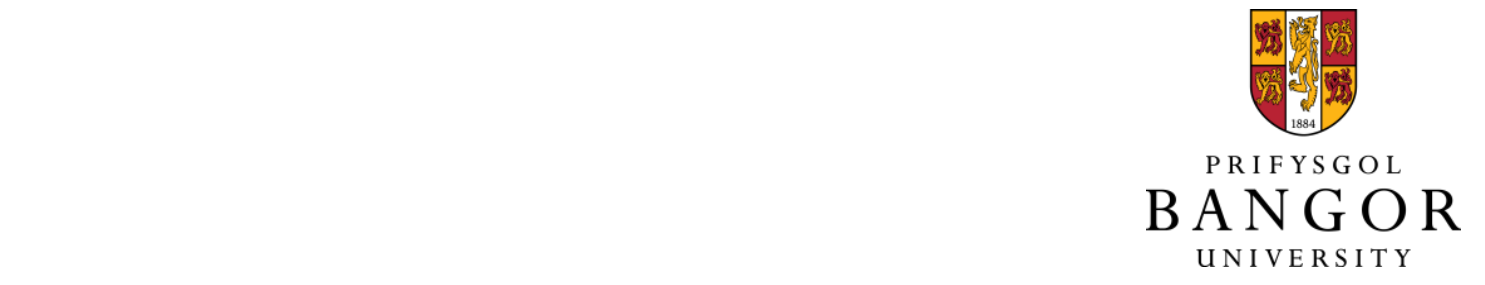

'Just not knowing' can make life sweeter (and saltier): Reward uncertainty alters the sensory experience and consumption of palatable food and drinks

Rauwolf, Paul; Mallard, Sammy ; Wong, Nicole; Witt, Alexandra; Davies,

Timothy; Cahill, Aaron; Madden, Gregory J ; Parkinson, John; Rogers, Robert Journal of Experimental Psychology: General

DOI:

$10.1037 / x g e 0001029$

Published: 01/10/2021

Peer reviewed version

Cyswllt i'r cyhoeddiad / Link to publication

Dyfyniad o'r fersiwn a gyhoeddwyd / Citation for published version (APA):

Rauwolf, P., Mallard, S., Wong, N., Witt, A., Davies, T., Cahill, A., Madden, G. J., Parkinson, J., \& Rogers, R. (2021). 'Just not knowing' can make life sweeter (and saltier): Reward uncertainty alters the sensory experience and consumption of palatable food and drinks. Journal of Experimental Psychology: General, 150(10), 2015-2035. https://doi.org/10.1037/xge0001029

\footnotetext{
Hawliau Cyffredinol / General rights

Copyright and moral rights for the publications made accessible in the public portal are retained by the authors and/or other copyright owners and it is a condition of accessing publications that users recognise and abide by the legal requirements associated with these rights.

- Users may download and print one copy of any publication from the public portal for the purpose of private study or research.

- You may not further distribute the material or use it for any profit-making activity or commercial gain

- You may freely distribute the URL identifying the publication in the public portal ?
}

Take down policy

If you believe that this document breaches copyright please contact us providing details, and we will remove access to the work immediately and investigate your claim. 
'Just not knowing' can make life sweeter (and saltier): Reward uncertainty alters the sensory experience and consumption of palatable food and drinks

Paul Rauwolfa

Sammy Millard ${ }^{b}$

Nicole Wong ${ }^{\mathrm{b}}$

Alexandra Wittc

Timothy J Davies ${ }^{\mathrm{a}}$

Aaron MCahill ${ }^{\mathrm{a}}$

Gregory J Madden ${ }^{\mathrm{d}}$

John A Parkinson ${ }^{\mathrm{a}}$

Robert D Rogers ${ }^{\mathrm{a}}$

aSchool of Psychology, Bangor University, Gwynedd, North Wales

bDepartment of Psychology, Bath University, Bath, Avon, BA2 7AY

'Department of Psychology, Technische Universitat Braunschweig Braunschweig, Lower Saxony, Germany

dDepartment of Psychology, Utah State University 2810 Logan, UT 84322

Corresponding author: Professor Robert D Rogers, School of Psychology, Adeilad Brigantia, Penrallt Road, Gwynedd LL57 2AS

r.rogers@bangor.ac.uk

Author Note: Some of these data were presented at the 2019 World Congress of Biological Psychiatry, 2-6 June 2019. The data for the four experiments are available at: https://osf.io/qdncm/

Declarations of interest: None

Word Count: 12,574 
2 Reward uncertainty can prompt exploration and learning, strengthening approach and

3 consummatory behaviours. For humans, these phenomena are exploited in marketing

4 promotions and gambling products, sometimes spurring hedonic consumption. Here, in four

5 experiments, we sought to identify whether reward uncertainty - as a state of 'not-knowing'

6 that exists between an action and a positively-valanced outcome - enhances the in-the-

7 moment consumption and experience of other palatable food and drink rewards. In

8 Experiment 1, we demonstrate that reward uncertainty can increase consumption of

9 commercial alcoholic drinks and energy-dense savoury snacks. In Experiment 2, we show

10 that reward uncertainty is unlikely to promote consumption through gross increases in

11 impulsivity (expressed as higher discounting rates) or risk-tolerance (expressed as lower

12 probability discounting rates). In Experiment 3, we find that reward uncertainty intensifies

13 taste of, and hedonic responses to, sucrose solutions in a concentration-dependent manner

14 among individuals with preferences for sweet tastes. Finally, in Experiment 4, we replicate

15 and extend these findings by showing that reward uncertainty intensifies the taste of palatable

16 foods and drinks in ways that are independent of individuals' discounting rates, motor control,

17 reflection impulsivity and momentary happiness; but are strongly moderated by recent

18 depressive symptoms. These data suggest a working hypothesis that (incidental) reward

19 uncertainty, as a state of 'not knowing', operates as a mood-dependent 'taste intensifier' of

20 palatable food and drink rewards, possibly sustaining reward-seeking and consumption.

22 Keywords: Hedonic consumption; reward uncertainty; consumption; taste; mood 
2 Adverse health experiences frequently involve problematic relationships with rewards

3 (Goodwin et al., 2015; Orford, 2000). Technology now facilitates continuous and low-cost

4 access to a substantially expanded range of powerful rewards including energy-dense

5 processed foods, alcohol and other psychoactive substances, gambling products, gaming,

6 pornography and social media (Goodwin et al., 2015; Ward, 2013). Heavy consumption of

7 these rewards tends to correlate within individuals (Goodwin et al., 2015); sometimes

8 producing enduring psychological and physical harms (Bellis et al., 2016; Orford, 2000;

9 Wardle et al., 2019). Learning more about the situational and psychological factors that

10 promote in-the-moment consumption of multiple rewards can help us to understand the

11 variety of peoples' consummatory behaviours and their linkages to adverse health outcomes.

12 Here, in four experiments, we report how 'incidental' uncertainty about the availability of one

13 powerful reward - money - can moderate individuals' consumption, and their experience, of

14 other directly consumable rewards - palatable, high-calories foods and drinks.

16 In foraging contexts, uncertainty about rewards - often operationalised as scarcity - drives exploration and learning (Anselme \& Güntürkün, 2019; Caraco et al., 1980; Ekman \& Hake, 1990). Unreliable signals of food rewards can capture attention more quickly than reliable signals (Pearce et al., 1982), strengthen approach behaviours and increase response rates (Anselme et al., 2013; Gottlieb, 2004). Strikingly, uncertainty involving one reward can promote consumption of another reward (Corwin, 2011; Falk, 1961; Wilson \& Cantor, 1987). In animal 'scheduled-induced', models, exposure to intermittent reinforcement schedules of food reward s can enhance 'adjunctive' consumption of alcohol (Falk, 1998; Falk et al., 1972; Samson \& Falk, 1974; Wilson \& Cantor, 1987). In humans too, experience of fluctuating operant reinforcement schedules for monetary rewards seems to alter cigarette consumption 
1 (Cherek, 1982); while uncertainty about instrumental contingencies can promote adjunctive

2 eating and drinking (Cantor et al., 1982). These observations suggest that it should be

3 possible to manipulate individuals' chance-based encounters with one palatable reward in

4 order to modulate their engagement with one or more other rewards.

6 Marketing strategists certainly seem to think so. Promotions involving uncertainty - Kinder

7 eggs, fortune cookies, consumer sweepstakes or competitions for bonus prizes (Kalra \& Shi,

8 2010) - can increase responsivity to advertisements (Wilcox \& Woodside, 2012), brand

9 loyalty (DelVecchio et al., 2006) and, possibly, purchasing behaviours through exaggerated

10 hedonic responses to low probability outcomes (O'Curry \& Strahilevitz, 2001). Loot Boxes,

11 involving the delivery of random (game-relevant) features purchased for real money, are a

12 salient aspect of online and video gaming (Zendle et al., 2020) and may strengthen harmful

13 patterns of play in some individuals (Li et al., 2019; Nielsen \& Grabarczyk, 2019). Random

14 rewards are also helpful in gamification (Burke, 2016), promoting engagement across, for

15 example, educational and health domains (Achananuparp et al., 2018; Dichev et al., 2015).

17 Most obviously, reward uncertainty is intrinsic to gambling, viewed (broadly) as the wagering of something of value based on future events determined, in part or wholly, by chance. For some gambling products, the intervals between purchase and resolution of the outcomes are extended over minutes, hours or days in ways that generate anticipatory utility and promote the savouring of future possibilities (Kocher et al., 2014; Loewenstein \& Elster, 1992); for example, buying a lottery ticket or placing a bet on a horse to win a race, waiting for the race to start and watching its completion. Other gambling products though involve brief but powerful states of anticipatory excitement and arousal (Ladouceur et al., 2003); the time it takes to scratch out the panel arrays on a scratch-card or the $2.5 \mathrm{~s}-4 \mathrm{~s}$ cycle of 
commercial slots-games (Worhunsky \& Rogers, 2018). The arousal generated during these

2 intervals, presumably mediated by the hypothalamic-pituitary-ad renal activity (Meyer et al., 2000; Meyer et al., 2004), could trigger other reward-seeking and consummatory behaviours.

5 The remaining limited evidence about how incidental reward uncertainty works in human

6 subjects suggests three things. First, that uncertainty experiences (of various kinds) increase

7 the use of affective information when making decisions about consumer goods (Faraji-Rad \&

8 Pham, 2017). Second, that incidental uncertainty can undermine self-control (as ego-

9 depletion) to promote the selection of 'want' options (that provide immediate gratification)

10 over 'should' options (that better support future well-being) (Milkman, 2012); or equivalently increase hedonic over functional consumption (Hirschman \& Holbrook, 1982). Finally, the utility derived from the resolution of uncertainty in consumer promotions, when the outcome of sweepstakes or competitions are revealed, augments the utility of acquisition to facilitate repeat purchases (Ruan et al., 2018; Shen et al., 2019). However, to date, here have been no direct tests of whether the incidental reward uncertainty inherent in consumer promotions or gambling products moderates the consumption and experience of other rewards.

\section{Our experiments}

Here, we focus upon the impacts of reward uncertainty on in-the-moment consumption, riskattitudes and responses to the sensory characteristics of primary-reinforcers: palatable food and drink rewards. In Experiment 1, we test whether reward uncertainty about monetary outcomes can facilitate consumption of commercial alcoholic drinks and palatable energydense food rewards. We find evidence that it does. In Experiment 2, we test whether increased consumption under conditions of reward uncertainty might reflect transient increases in impulsivity or risk-tolerance (measured as delay and probability discounting) 
1 (Bickel et al., 2014; Odum, 2011; Petry, 2001; Rasmussen et al., 2010; Stojek \& MacKillop,

2 2017). We find little evidence that this is the case. In Experiment 3, we test whether reward

3 uncertainty modulates the experience of rewards in ways that could facilitate consumption

4 (Casperson et al., 2019; Lenoir et al., 2007; van Opstal et al., 2020). We find that reward

8 Finally, in Experiment 4, we attempt to valid ate and replicate the previous results, and test

uncertainty about monetary outcomes makes sweet drinks taste sweeter and elevates hedonic responses among individuals with preferences for high-intensity sweet tastes.

whether reward uncertainty particularly affects individuals exhibiting risk factors for overconsumption. Harmful consumption of alcohol and high-energy food rewards is linked to, not only rapid delay and probability discounting (Bickel et al., 2014; Odum, 2011; Petry, 2001; Rasmussen et al., 2010; Stojek \& MacKillop, 2017), but relatively poor motor inhibition (Bartholdy et al., 2016; Lawrence et al., 2015; Nederkoorn et al., 2010) and a predisposition to quick decisions over information-gathering (Banca et al., 2015). Over-consumption of food, alcohol and gambling products is also motivated by the alleviation of anxiety and depressive states (Blaszczynski \& Nower, 2002; Lloyd et al., 2010; Stevenson et al., 2019; van Strien et al., 2016). We find evidence that the effects of reward uncertainty about monetary outcomes on the sensory experiences of palatable food and drink rewards are not much moderated by cognitive factors but are moderated by depressive symptoms, suggesting a mood-dependent 'taste intensifying' mechanism that can fuel consumption.

One critical design challenge involves how we operationalised uncertainty. Uncertainty about pleasurable events can enhance and prolong improvements in mood, both in ambiguous situations or those involving 'Knightian' uncertainty (Bar-Anan et al., 2009; Ellsberg, 1961; Wilson et al., 2005) and in the presence of explicit probability cues (in risk-based scenarios) 
1 (Kurtz et al., 2007; Whitchurch et al., 2011). However, the extant evidence about the impacts

2 of incidental reward uncertainty across appetitive behaviours in animals often involve operant

3 preparations with intermittent reinforcement schedules that must be learned following

4 extended training with fluctuating experiences of reward delivery (Falk et al., 1972; Falk \&

5 Tang, 1988; Zack et al., 2014; Zeeb et al., 2017). Other evidence with human subjects

6 indicates that the evaluation of prospects with explicit probability information consistently

7 engages affective processes that drive individuals' responses to risk (Lowenstein et al., 2001;

8 Slovic et al., 2005) and that people will choose to defer the resolution of fully-specified risk-

9 based gambles in order to savour the resulting anticipatory cognitive and affective states

10 (Ahlbrecht \& Weber, 1996; Lovallo \& Kahneman, 2000). Games with dice are a common,

11 life-long and at least relatively culture-fair feature of our everyday experiences with explicit

12 risk-based probabilities. Therefore, here, we manipulate incidental reward uncertainty, as a

13 state of 'not-knowing' the outcome of a single fair, 6-sided die-roll for monetary prizes, and

14 test its impacts on consumption and other reward experiences.

\section{Experiment 1}

17 To start, we examine whether the experience of incidental reward uncertainty about monetary outcomes can facilitate the consumption of a different reward that is ubiquitous in gambling venues: branded alcoholic beverages. Gambling venues provide a variety of complementary foods, drinks and other goods as part of the long-established practice to increase gambling session length and encourage expenditure (Bobo \& Husten, 2000; Giacopassi et al., 1998). Exposure to simulated gambling environments have been shown to increase ghrelin release in a mixed sample of non-problem and problem gamblers, with plasma concentrations being positively associated with the persistence of (losing) slot-machine play (Sztainert et al., 2018); potentially spurring broader food and drink-seeking consumption. 
1 Typically, the links between alcohol consumption and gambling are considered from the one

2 direction: in terms of alcohol facilitating individuals' betting behaviours by reducing

3 inhibitory and other forms of self-control (Cronce \& Corbin, 2010; Ellery, 2005; Kyngdon,

4 1999; Stewart et al., 2005). Much less is known about the reverse possibility: that aspects of

5 gambling enable other forms of reward-seeking and consumption. Tobias-Webb et al (2019)

6 showed that 30 minutes of slot-machine play (with one other individual present in a simulated

7 casino environment) increased the number of alcoholic drinks ordered, volume of alcohol

8 consumed, speed of consumption and intentions-to-drink (Tobias-Webb et al., 2019). While

9 these data suggest that engagement with the common gambling form of slots facilitates

10 alcohol intake, they are confounded with the emotional ups-and-downs of play outcomes and do not isolate reward uncertainty as a mediating mechanism. So, in our first experiment, we tested the hypothesis that the experience of incidental reward uncertainty about money facilitates in-the-moment consumption of alcohol and, possibly, palatable high-calorie foods.

In outline, participants were randomised to one of three groups. Initially, we were interested in testing whether the effects of reward uncertainty were modulated by its framing in terms of gains or losses (Levin et al., 1998; Tversky \& Kahneman, 1981). Two groups were invited to roll a single fair 6-sided die to determine the value of their final participation fee. The positively-framed participants were told that their fee for participating in the experiment was $£ 3$ but that, if they rolled a ' 1 ' or a ' 2 ', this payment would increase to $£ 24$. The negativelyframed participants were told that their participation fee was now $£ 24$ but that, if they rolled a '3', '4', '5', or '6', this payment would fall to $£ 3$. Neither group was informed about the outcome of the die-roll until the end of the protocol, inducing a state of reward uncertainty as 'not-knowing' the result of this single and (for student participants) high-value prospect. The third ('control') group of participants was simply given the expected value of the die-roll (i.e. 
$1 £ 7)$ as a bonus payment or windfall added to their participation fee of $£ 3$. Thus, the expected

2 value of the reward-induction and control protocols were matched across the three groups.

3

4 All participants then completed a 'bogus taste test' (Robinson et al., 2017) of savoury 'pub

5 snacks' but were offered the opportunity to sample and drink one of a selection of chilled

\section{Methods}

11 Experiment 1 was approved by Bangor University (School of Psychology) Ethics Committee. well-known commercially bottled alcoholic lagers. We tested the prediction that reward uncertainty in the positively- and negatively-framed participants would be associated with the consumption of a higher volume of alcoholic drinks compared with the control participants.

$$
\text { All participants provided written, informed consent. }
$$

\section{Participants}

One hundred and seven adults were recruited from Bangor University's School of Psychology student participant panel, taking part in exchange for course credits and the baseline $£ 3$ payment. Since we wished to test the opportunistic consumption elicited by incidental reward uncertainty, participants were not required to restrict their normal food and liquid beforehand.

Participants were assessed against minimal exclusion criteria of (i) self-reported food allergies; (ii) current alcohol abstinence and (iii) alcohol dependence as indicated by scores of 15 or more on the Alcohol Use Disorders Identification Test (AUDIT; Saunders, Aasland, Amundsen, \& Marcus, 1993). Seventeen participants were excluded because they indicated, at the outset, that they would not consume any of the alcoholic beverage during the protocol. This left a final sample of 51 female and 39 male participants $(M=22.88, S E=0.34 \mathrm{yrs})$. 
2 Experiment 1 consisted of a between-subject design in which participants were randomised to one of three experimental groups: the positively-framed; the negatively-framed; and control

4 participants. There were 13 males and 17 females in each participant group.

5

6 Self-report questionnaires

7 Participants completed the following psychometric questionnaires: (i) the state version of

8 'Positive And Negative Affect Schedule' (PANAS-S; Watson, Clark, \& Tellegen, 1988) and

9 (ii) the Alcohol Use Disorders Identification Test (AUDIT; Saunders, Aasland, Amund sen, \& 10 Marcus, 1993). Participants provided ratings of momentary hunger and thirst. The 'bogus taste test' consisted of momentary ratings of how much participants wanted to eat the food rewards and how much they liked the food rewards. All of these measurements were taken with $10 \mathrm{~cm}$ visual analogue scales (VAS) with anchor points of 'Not at all' and 'Very Much'.

The protocol for Experiments 1 through 4 included several additional questionnaires for exploratory purposes. These are listed in full in Supplemental Material A.

\section{Procedure - reward uncertainty induction and 'bogus taste test'}

Upon arrival at the laboratory, participants were told they were going to take part in a consumer taste test for 'pub snacks'. Participants provided demographic information and also ratings of their current state of hunger and thirst. They also completed the AUDIT (Saunders et al., 1993) and PANAS-S questionnaires (Watson et al., 1988).

24 Next, the participants of the positively-framed and negatively-framed groups were informed that their payment for taking part might be as much as $£ 24$. To strengthen the image-ability of 
1 this prospect, participants were asked to write a short paragraph to describe how they might

2 spend the $£ 24$ in a guilt-free way on themselves or someone close, and how they might feel

3 about it. Following this, these participants were introduced to a motorised device for rolling a

4 6-sided die inside a transparent, plastic cover (see Supplemental Material B and Figure S1 for

5 a photograph). Participants were asked to push a button on the side of the device to roll the die

6 as many times as they wished until they were fully satisfied that the die was fair. At this point,

7 the positively- and negatively-framed participants were informed that their payment for taking

8 part in the experiment would depend on the outcome of a single roll of the die. Participants in

9 the positively-framed group were informed their payment would include the baseline payment of $£ 3$ but, if they rolled a ' 1 ' or a '2', they would win a further $£ 21$, increasing their final payment to $£ 24$. However, rolling a '3', '4', '5' or '6' would leave their payment at $£ 3$. By contrast, the participants in the negatively-framed group were informed their payment would be $£ 24$, and if they rolled a '1' or '2', their payment would remain at $£ 24$. Rolling a '3', '4', '5' or ' 6 ' would mean they lost $£ 21$ and their payment would be reduced to $£ 3$.

Finally, the die-rolling device was covered with a black opaque cover to obscure the outcome of the die-roll (and thus the value of their final payment) until completion of the experimental protocol. Participants rolled the die and placed the device, with a black cover in place, in a small plastic transparent box. The box also contained the cash to value of the base participation fee $(£ 3)$ and the higher value outcome of the die-roll: two $£ 10$ notes, and four $£ 1$ coins. Participants locked the box and passed the key to the experimenter. The box and its contents were positioned in front of the participants for the remainder of the protocol.

Participants in the control group were not shown either the die-rolling device or die. Instead, they were informed that their payment would include the baseline $£ 3$ plus a gift of an extra $£ 7$, 
1 to yield a total payment of $£ 10$. (We chose the bonus value of $£ 7$ since it is the expected value

2 of the die-roll outcome for both the positively- and negative-framed participants)

4 In the 'bogus taste test' (Robinson et al., 2017), bowls of snacks (e.g. crisps, pretzels,

5 Cheetos $^{\mathrm{TM}}$, Hula Hoops ${ }^{\mathrm{TM}}$ ) were placed in front of participants. They were asked to try every

6 snack and provide ratings of how much they wanted and liked each of them using the $10 \mathrm{~cm}$

7 VAS. Once participants had placed the first snack in their mouth, it was interjected that, since

8 the taste test involved 'pub snacks', they would have access to a commercial lager to drink.

9 Participants chose a chilled bottle of beer from a glass-fronted fridge (Becks ${ }^{\mathrm{TM}}$, Budweiser ${ }^{\mathrm{TM}}$

10 or Coors light $\left.{ }^{\mathrm{TM}}\right)$. The experimenter poured the beer and placed it beside the snacks.

12 Once participants had provided wanting and liking ratings for the available snacks, they watched a 10-minute segment of 'The Simpsons'. During this time, they were free to eat and drink as they wished. Following the end of the Simpsons segment, the experimenter cleared away the snacks and beer to be weighed later on. Participants provided final PANAS-S, hunger and thirst ratings. Finally, the experimenter unlocked the plastic box, recovered the die-rolling device, and removed the black cover to reveal the outcome of the die-roll and the value of participants' final payment. Participants were then discharged.

\section{Results}

\section{Group-matching}

22 Participants in the positively and negatively-framed groups did not differ in their alcohol or 23 snack consumption (see Supplemental Material C for details). So, for the purposes of clarity and power, we collapsed the two groups into one 'reward-uncertain' group and compared them with the control group. Regression and $\chi^{2}$-tests showed that the reward-uncertain and control 
1 groups were closely matched in terms of gender $\left(17: 13\right.$ vs $\left.34: 26 ; \chi^{2}(1)=0.00, p=1\right)$, age

$2 \quad(23.6 \pm 0.58$ vs $22.5 \pm 0.41 \mathrm{yrs} ; \beta=-1.08 ; p=0.14)$, positive affect $(30.1 \pm 1.01$ vs $28.17 \pm 1.77$;

$3 \quad \beta=1.88 ; p=0.33)$, negative affect $(11.87 \pm .36$ vs $12.7 \pm .55 ; \beta=-0.87 ; p=0.18)$, pre-induction

4 hunger and thirst ratings $(3.55 \pm .34 \mathrm{vs} 3.66 \pm .41 ; \beta=-0.077 ; p=0.89$ and $4.16 \pm .37$ vs $4.43 \pm .43$;

$5 \beta=-0.273 ; p=0.65$, respectively) (Supplemental Material D/Table S1 for group characteristics).

\section{$7 \quad$ Alcohol and snack consumption}

8 Figure 1(left) shows the average alcoholic drink consumption (ml) in the reward-uncertain

9 and control groups. Participants who experienced reward uncertainty about the die-roll and its monetary outcomes clearly drank the most. We tested this with a linear regression model of the form: Alcohol Consumption $=$ Gender + Reward Uncertainty, boot-strapped 1,000 times . Male participants consumed more of the alcoholic drink than the females $(\beta=75.3 \mathrm{ml} ; 95 \% \mathrm{CI}$ $[-105.60,-42.16])$. The reward-uncertain participants drank markedly more of the alcoholic drinks compared with those of the control participants ( $\beta=48.4 \mathrm{ml}$; 95\% CI $[12.47,84.96])$.

Since the reward-uncertain participants reported very slightly higher AUDIT scores than the

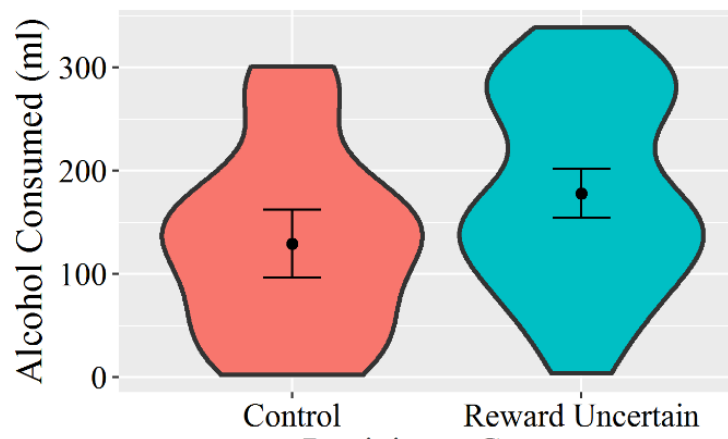

Participant Group

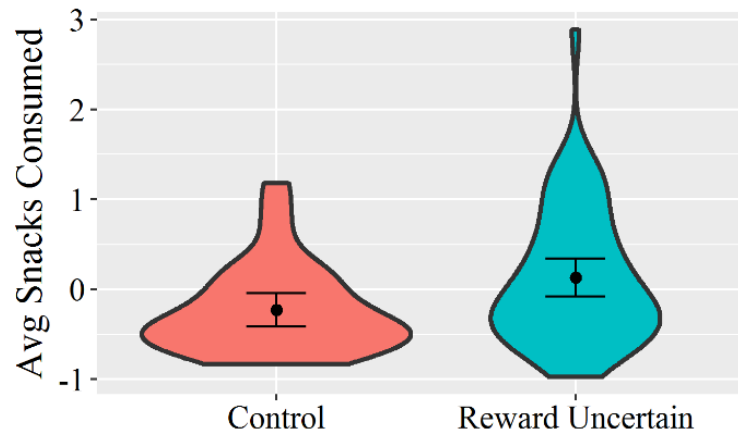

Participant Group

Figure 1 Violin plot of the amount consumed by the reward-uncertain group and control groups in Experiment 1. Left: Millimetres of alcohol consumed. Right: Average normalised snacks consumed. The shape of each group figure represents the density of participants' consumption. Error bars represent $95 \%$ confidence intervals. 
1 added AUDIT scores to the boot-strapped model. It still showed with $95 \%$ confidence, that

2 reward uncertainty increased the volume of beer consumed ( $\beta=40.3 \mathrm{ml}$; 95\% CI [7.77, 78.28]).

3

4 For each snack, we normalised the weight consumed to a mean of zero and a standard deviation of one. Participants' consumption was calculated as the average of each normalized snack ( 1 control and 9 reward-uncertain participants were removed as consumption weights were unavailable). Figure 1(right) illustrates the average consumption for the two participant groups. Those in the reward-uncertain group ate the most. A linear model of the form, Snack Consumption $=$ Gender + Reward Uncertainty, boot-strapped with 1,000 runs, showed that females tended to eat marginally less than males $(\beta=-0.257 ; 95 \%$ CI $[-0.6019$, 0.0431]). As with the alcoholic drinks, the reward-uncertain participants also consumed more of the pub snacks than the control participants $(\beta=0.365 ; 95 \%$ CI $[0.1188,0.6669])$.

None of the above findings were markedly influenced by participants' current motivational state. Adding in the pre-induction hunger and thirst ratings to the models made little difference to the estimated increase in the volume of alcoholic beer or the amount of snacks consumed by the reward-uncertain participants compared with the control participants ( $\beta=37.96 \mathrm{ml} ; 95 \%$ CI $[3.16,71.73]$ and $\beta=0.38 ; 95 \%$ CI $[0.11,0.64]$, respectively).

\section{Wanting and Liking}

21 Finally, we tested whether reward uncertainty influenced how much participants (i) wanted to eat and (b) liked the snacks. A boot-strapped model of the form: Wanting (or Liking) = Gender + Reward Uncertainty showed that the reward-uncertain group reported modest but non-significant increases in wanting of the snacks compared with the controls $(53.518 \pm 3.081$ 

across the two groups $(54.397 \pm 3.580$ vs $55.952 \pm 2.850 ; \beta=1.30 ; 95 \%$ CI $[-7.550,10.961])$.

\section{Discussion}

5 Experiment 1 tested the preliminary hypothesis that reward uncertainty about a monetary

6 outcome - inherent in gambling products and other reinforcement environments - can

7 increase consumption of other palatable rewards like commercial alcoholic beers. Utilising a

8 'bogus taste test' (Robinson et al., 2017), the results showed that the participants of the

9 reward-uncertain group consumed substantially greater volumes of personally selected - and presumably, preferred - branded commercial bottled beer compared with the participants of the control group. In addition, the reward-uncertain participants ate greater amounts of 'pub snacks', indicating that the facilitatory effects of incidental reward uncertainty on individuals' hedonic consumption behaviours extend to palatable and energy-dense edible foods.

Gambling while drinking in casinos, horse- or dog-racing tracks, or in the context of private premises are common - perhaps almost normative - experiences (Bobo \& Husten, 2000;

Giacopassi et al., 1998). Typically, the risks associated with this co-consumption have been viewed from one direction: how alcohol's disinhibitory effects can prolong gambling sessions and increase individuals' losses, increasing the risks of gambling harms (Cronce \& Corbin, 2010; Ellery, 2005; Kyngdon, 1999; Stewart et al., 2005). Here, complementing animal models (Anselme et al., 2013; Falk, 1998; Falk et al., 1972; Falk \& Tang, 1988; Robinson et al., 2015; Samson \& Falk, 1974; Wilson \& Cantor, 1987; Zack et al., 2014; Zeeb et al., 2017), Experiment 1 indicates that the reward uncertainty intrinsic to gambling products can enhance in-the-moment alcohol intake, suggesting that the co-consumption of gambling, alcohol and other rewards is likely cyclical or cross-facilitatory. 
1 Several mechanisms might account for these findings. Reward uncertainty may increase

2 preferences for hedonic 'want' good s over functional, 'should' goods (Hirschman \& Holbrook,

3 1982; Milkman, 2012). Possibly, this involves activated incentive-salience processes

4 (Anselme et al., 2013; Robinson et al., 2015) such that, in Experiment 1, reward uncertainty

5 enhanced participants' 'wanting' of the alcoholic beer and pub snacks through the enhanced

6 salience of recognisable branded bottles or food od ours encountered while waiting to learn

7 the outcome of the die-roll (and value of the final payment). There was though evidence of

8 only modest increases in self-reported 'wanting' of the pub snacks in the reward-uncertain

9 compared with the control participants. By contrast, another possibility is that incidental

10 reward-uncertainty interrupts individuals' self-control (Milkman, 2012), promoting their engagement with other rewards. Experiments $2 \mathrm{a}$ and $2 \mathrm{~b}$ tests this possibility.

\section{Experiment 2}

14 Experiment 1 showed that incidental uncertainty about monetary rewards increased consumption of both alcoholic beers and palatable foods. Other reports posit reward uncertainty is experienced as effortful and that it exhausts self-control as a psychological 'muscle' (ego-depletion), promoting the selection of 'want' over 'should' options (Milkman, 2012) and hedonic over functional consumption (Hirschman \& Holbrook, 1982). If this is the case, we might expect the effects of incidental reward uncertainty to be expressed in preferences for sooner smaller over larger later rewards; i.e. higher delay discounting rates.

Hazardous consumption of alcohol (Amlung et al., 2017; Petry, 2001) and food rewards

(Barlow et al., 2016; Bickel et al., 2014; Fields et al., 2013; Hendrickson \& Rasmussen, 2013;

Manwaring et al., 2011; Rasmussen et al., 2010; Stojek \& MacKillop, 2017) are linked to impulsivity as the rapid discounting of rewards with the time intervals to their receipt or 
1 consumption (Odum, 2011). Experimental work suggests that psychological interventions can

2 counter impulsivity by transiently reducing delay discounting rates (Rung \& Madden, 2018).

3 Of these, the most relevant for us are manipulations that focus individuals' attention on longer

4 time horizons (Zauberman et al., 2009) and the anticipated experience of future events (Daniel

5 et al., 2015; Daniel et al., 2013; Peters \& Buchel, 2010; Snider et al., 2016); or involve the

6 presentation of positively-valanced stimuli to favour one-off selections of delayed rewards

7 (Berry et al., 2014). Although these reports all involve attempts to reduce impulsivity by

8 transiently decreasing delay discounting rates (Rung \& Madden, 2018), other circumstances -

9 perhaps, those involving incidental reward-uncertainty - might have the opposite effect and induce impulsivity by increasing discounting rates, promoting in-the-moment consumption.

So, in Experiment 2a, we tested the hypothesis that reward uncertainty, as 'not-knowing', transiently increases preferences for smaller sooner over larger later rewards.

Beyond testing whether reward uncertainty influences delay discounting, we also tested whether it can alter probabilistic discounting. Although less consistent than the evidence involving delay discounting, health problems involving obesity and weight gain have been linked to risk-tolerance, operationalised as the tendency to show less discounting of lower probability compared with higher probability rewards (Bickel et al., 2014; Hendrickson \& Rasmussen, 2013; Madden et al., 2009; Rasmussen et al., 2010; Reynolds et al., 2004).

Prolonged exposure to reward uncertainty can potentiate behavioural responses to (conditioned) stimuli via dopaminergic modulation of reinforcement circuits that encode risk (Anselme et al., 2013; Fiorillo et al., 2003; Robinson et al., 2015; Schultz et al., 2008; Zack et al., 2014), promoting risk-tolerance and risky patterns of decision-making (Zeeb et al., 2017).

So, Experiment $2 \mathrm{~b}$ tested the additional hypothesis that reward uncertainty experiences increase individuals' risk-tolerance by decreasing their discounting rates of probabilistic 
rewards. Following previous investigations of reward uncertainty in human subjects (Faraji-

2 Rad \& Pham, 2017; Milkman, 2012), and to increase statistical power, Experiments 2a and 2b used the online participant panel, Amazon Mechanical Turk (https://www.mturk.com/).

4

5 Testing the effects of reward uncertainty on delay and probability discounting involves several challenging design decisions about the kind of rewards offered to participants and the most appropriate discounting elicitations (see Supplemental Materials E for a discussion). Numerous studies show no systematic differences between discounting rates when rewards are real or hypothetical (Johnson \& Bickel, 2002; Lagorio \& Madden, 2005; Madden et al., 2003) and statistical equivalence of real and hypothetical rewards in delay and probability discounting elicitations (Matusiewicz et al., 2013). In Experiments 2a and 2b, we tested whether reward uncertainty induces general perturbation of delay discounting and risktolerance (as measured by a probability discounting elicitation) for hypothetical rewards.

\section{Experiment 2a: Method}

16 Experiment 2a was approved by Bangor University (School of Psychology) Ethics

17 Committee. At the beginning of the online survey, participants read a single-page description of the experiment and clicked a single radio-button to provide informed consent.

\section{Participants}

21 Two-hundred participants were recruited using Amazon Mechanical Turk (MTurk). All participants were compensated $\$ 1$ for completing a 5-10 minute online survey. One participant was excluded for non-completion. This left 199 participants $(M=34.06, S E=0.70$, comprised of 115 males $(M=31.94, S E=0.73)$ and 84 females $(M=36.96, S E=1.25)$. 


\section{Design}

2 Experiment 2 a consisted of a between-subject design where participants were randomised to 3 one of two groups: the reward-uncertain $(\mathrm{N}=107)$ or the control group $(\mathrm{N}=92)$.

4

\section{$5 \quad$ Self-report questionnaires}

6 Participants provided ratings of positive affect as momentary happiness ('How happy are you

7 right now?') and alertness ('How alert are you right now?') using 15-point Likert scales with

8 the anchor points of 'Not at all' and 'Extremely'. (A description of the changes in momentary

9 happiness and alertness (pre-induction, post-induction and post-outcome) in the rewarduncertain compared with the controls of Experiments $2 \mathrm{a}$ and $2 \mathrm{bs}$ are provided in Supplemental Material F/Tables S4 and S5). At the end of the survey, participants completed the WHO-5 assessment of subjective well-being (Topp et al., 2015) and a measure of early-year socioeconomic status (SES) (Griskevicius et al., 2011). Neither measure showed associations with the effects of reward-uncertainty and are not discussed here (Rauwolf et al., 2020, August 28).

\section{Procedure}

First, participants provided demographics of age, gender, and occupation, along with preinduction ratings of momentary happiness and alertness. Next, participants who had been randomised to the reward-uncertain group were informed that they would roll a simulated but fair 6-sided die to win additional money (Supplemental Material B for a photograph). The reward-uncertainty induction was modelled on the positively-framed version of Experiment 1; that is, the monetary pay-offs of the die-roll were couched in terms of payments gained.

The die-roll was generated with JavaScript. Participants clicked a button to roll the die as many times as necessary to satisfy themselves that the die was fair. Once participants were 
1 content to proceed, they were informed that if they rolled a '1' or a '2', their participation fee

2 would be increased by an additional $\$ 4$ for a total payment of $\$ 5$. If they rolled a '3', '4', '5' or

3 '6', they would receive no bonus and leave with the original \$1. Participants then clicked once

4 more to roll the die but this time the result was hidden (see Supplementary Material B/Figures

5 S2 and S3) and only revealed at the end of the protocol. Participants in the control group were

6 informed that they would receive an additional $\$ 1.33$ (the expected value of the die-roll) as a

7 bonus payment. Thus, they received $\$ 2.33$ for completing the entire survey. All participants

8 then completed a pair of post-induction 15-point Likert ratings of happiness and alertness.

10 Next, participants completed the 5-item (and 2min) ED50 elicitation of delay discounting

11 (Koffarnus \& Bickel, 2014). Its forced-choice items asked participants whether they preferred $\$ 500$ now or $\$ 1,000$ at some later variable delay. The $\mathrm{ED}_{50}$ elicitation attempts to find the delay (between $1 \mathrm{hr}$ and 25yr) when individuals' preferences switch from the immediate small reward to the delayed large reward.

Following the completion of the $\mathrm{ED}_{50}$ elicitation, the participants of the reward-uncertain group were shown the outcome of the hidden die-roll. Next, all participants completed the WHO-5 assessment of subjective well-being (Topp et al., 2015), and the SES measure of early-year socio-economic status (Griskevicius et al., 2011). Finally, all participants provided post-outcome ratings of momentary happiness and alertness before the survey terminated.

\section{Results}

\section{Group-matching.}

24 The reward-uncertain participants were slightly younger than the control participants 
1 vs 58:32; $\left.\chi^{2}(1)=2.07, p=.14\right)$. The reward-uncertain group and the control group were closely

2 matched for their pre-induction happiness and alertness (10.92 \pm 0.30 vs $11.14 \pm 0.34 ; \beta=-0.225$,

$3 p=0.617$ and $12.48 \pm 0.24$ vs $12.28 \pm 0.26 ; \beta=0.192, p=0.586$, respectively).

4

\section{Delay discounting rates}

$6 \quad$ Participants' delay discounting rates ( $k$ values) were calculated as per Koffarnus \& Bickel

7 (2014); the larger the value of $k$, the less time a participant was willing to wait for $\$ 1,000$,

8 compared with taking $\$ 500$ immediately. Figure 2(left) depicts the average discounting rates

9 for the two groups. $k$ was not normally distributed and so the log-transformed value was used.

10 Gender was added as a covariate since male participants reported higher $k$ values than female

11 participants $(\beta=0.8345 ; 95 \%$ CI $[0.122,1.509])$.

12

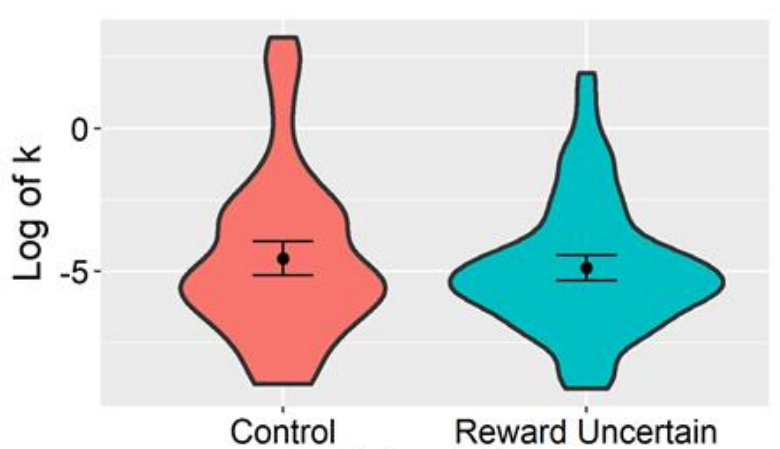

Participant Group

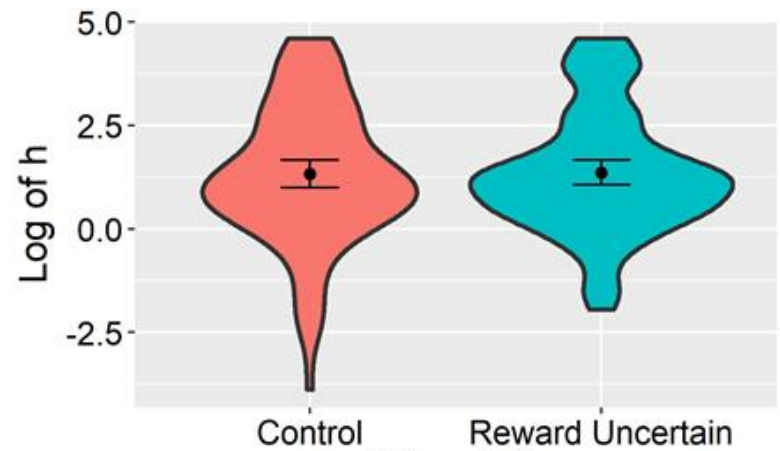

Participant Group

Figure 2 Violin plots representing the distribution of each group for temporal discounting (Experiment 2a) and probabilistic discounting (Experiment 2b). Left: The log of $k$ from the ED 50. Right: The log of $\mathrm{h}$ from the $\mathrm{EP}_{50}$. Dots represent the average value by group, and error bars represent confidence intervals of the mean.

A regression of the form: $\log (k)=$ Gender + Reward Uncertainty, boot-strapped 1,000 times, showed no marked differences in discounting rates between the reward-uncertain and control participants $(\beta=-0.2536 ; 95 \%$ CI $[-1.0236,0.4443])$, suggesting that reward uncertainty does not induce transitory increases in preferences for smaller, sooner over larger, later rewards. 


\section{Experiment 2b: Method}

2 Experiment $2 \mathrm{~b}$ was approved by Bangor University (School of Psychology) Ethics

3 Committee. At the beginning of an online survey, all participants read a single-page

4 description of the experiment and clicked a single radio-button to provide informed consent.

\section{Participants}

7 Two-hundred participants $(M=36.46, S E=0.85)$ were recruited using MTurk. There were 114 8 males $(M=35.25, S E=1.00)$ and 86 females $(M=38.05, S E=1.45) ; 101$ participants randomised 9 to the reward-uncertain group and 99 to the control group.

\section{Procedure}

The protocol was identical to Experiment 2a, with the single exception that we replaced the ED50 delay discounting elicitation with the $\mathrm{EP}_{50}$ probability discounting elicitation (Cox \& Dallery, 2016). This elicitation offers forced-choice options between hypothetically receiving $\$ 500$ for certain or receiving $\$ 1,000$ with probability $p$ and finds the probability where preference switches from the certain smaller to the less probable larger amount.

\section{Results}

\section{Group-matching}

The reward-uncertain and control participants were closely matched in terms of gender (M:F ratios: $53: 48$ vs $\left.61: 38 ; \chi^{2}(1)=1.352, p=.245\right)$ and their ages $(35.97 \pm 1.11$ vs $36.94 \pm 1.29 \mathrm{yrs}$, respectively; $\beta=-0.98 . p=0.56)$. Pre-induction happiness and alertness were comparable between the reward-uncertain and control groups $(10.82 \pm 0.31$ vs $11.45 \pm 0.29, \beta=-0.633$, $p=0.14$ and $12.04 \pm 0.27$ vs $12.47 \pm 0.25, \beta=-0.435, p=0.24$, respectively). 


\section{Probability discounting rates}

2 Probability discounting rates $(h)$ were calculated as per Cox \& Dallery (2016). The smaller the

3 value of $h$, the more risk a person is willing to tolerate in order to acquire $\$ 1,000$, as opposed

4 to receiving $\$ 500$ for certain. Figure 2(right) depicts the average value of the log of $h$ for the

5 two participant groups. A linear model, boot-strapped 1,000 times, of the form: $\log (h)=$

6 Gender + Reward Uncertainty showed that males accepted more risk than females $(\beta=-$

$7 \quad 0.6239 ; 95 \%$ CI [-1.0381, -0.1486]). However, there was no marked reduction (or change) in

8 the discounting of probabilistic rewards in the reward-uncertain compared with the control

9 participants $(\beta=-0.0230 ; 95 \%$ CI $(-0.4631,0.4466])$, suggesting that reward uncertainty does not transiently increase risk-tolerance, to promote broader consumption.

\section{Discussion}

13 Experiment 1 shows that reward uncertainty experiences can facilitate consumption of alcohol and palatable food rewards. Other data indicates that consumption of these rewards is linked to enhanced impulsivity, as preferences for smaller, sooner rewards at the expense of larger later rewards (Amlung et al., 2017; Barlow et al., 2016; Bickel et al., 2014; Fields et al., 2013; Manwaring et al., 2011; Petry, 2001; Stojek \& MacKillop, 2017) or risk-tolerance (Hendrickson \& Rasmussen, 2013; Rasmussen et al., 2010; Reynolds et al., 2004). Experiments $2 \mathrm{a}$ and $2 \mathrm{~b}$ tested the hypotheses that incidental reward-uncertainty changes these risk-attitudes in ways that facilitate in-the-moment consumption of palatable rewards. We find no evidence of the gross changes in individuals' delay and probability discounting rates that are detectable with the brief, validated elicitations involving hypothetical monetary rewards (Cox \& Dallery, 2016; Koffarnus \& Bickel, 2014). Other data indicate that delay and probability discounting rates can be steeper for directly consumable compared with monetary rewards (Odum et al., 2006; Rasmussen et al., 2010), raising the possibility that incidental 
reward uncertainty might yet promote consumption by transiently increasing impulsivity or

2 risk-tolerance for food and drink rewards specifically. However, Experiments $2 \mathrm{a}$ and $2 \mathrm{~b}$

3 indicate that any such impulsivity-generating processes under conditions of uncertainty are

4 likely to be reward-and situation-specific (see Supplemental Material E for discussion).

\section{Experiment 3}

7 In Experiment 1, we found that reward uncertainty experiences increase in-the-moment

8 alcohol and snack consumption. In Experiment 2, we showed that this increased consumption

9 is unlikely to arise because reward uncertainty produces gross changes in impulsivity expressed as increased delay discounting or risk tolerance. In Experiment 3, we switched tack.

11 We hypothesised that reward uncertainty modulates the experience of rewards in ways that might promote their in-the-moment consumption; focusing on the powerful reward of sweet tastes (Lenoir et al., 2007; Moskowitz et al., 1974; van Opstal et al., 2020). Specifically, we tested the prediction that incidental uncertainty, as a state of not-knowing about the outcome of a fully specified risk-based monetary prospect, enhances individuals' responses to the taste characteristics of, and hed onic responses to, increasing concentrations of sucrose solutions.

Further, harmful consumption of alcohol (Kampov-Polevoy et al., 1997; Kampov-Polevoy et al., 2003; Kranzler et al., 2001), cocaine (Janowsky et al., 2003) and food rewards (Krahn et al., 2006) are linked to preferences for the intensity of high concentration sweet tastes; in socalled 'sweet-likers' (Kampov-Polevoy et al., 2003; Kranzler et al., 2001; Levine et al., 2003). Sweet-likers can show rapid delay discounting rates (Weafer et al., 2014) as a risk factor for these health experiences (Amlung et al., 2017; Barlow et al., 2016; Hendrickson \& Rasmussen, 2013; Petry, 2001; Rasmussen et al., 2010; Stojek \& MacKillop, 2017) and, in some reports, patterns of increased food consumption (Kampov-Polevoy et al., 2006; Tan \& 
1 Tucker, 2019). These bidirectional associations suggest that individuals who prefer the

2 strongest concentration sweet tastes will be particularly sensitive to the effects of reward

3 uncertainty. So, in Experiment 3, we worked with two datasets; first, an unselected sample of

4 young male and female participants but then, second, a large sub-sample of sweet-likers.

5

6 Finally, consumption of alcohol, food, drugs and gambling products all have mood-regulatory

7 functions in the alleviation of stress, anxiety or depression in vulnerable individuals (Boden \&

8 Fergusson, 2011; Konttinen et al., 2019; Lloyd et al., 2010). So, we measured participants'

9 depressive symptoms using the BDI-II (Beck et al., 1996), in order to explore whether the

10 effects of reward uncertainty on responses to sweet tastes is moderated by mood.

12 Method

13 Experiment 3 was approved by Bangor University (School of Psychology) Ethics Committee. 14 All participants provided written, informed consent. The method was similar to Experiment 1 15 but replaced the bogus taste test with a sweetness taste test (Weafer et al., 2014).

\section{Participants}

18 Power analysis using the data from Experiment 1 indicated that $80 \%$ power (at $95 \%$

19 confidence) to detect changes in alcohol consumption and snack consumption required 126

20 and 135 participants, respectively (see Supplementary Materials G). One hundred and forty-

21 three participants were recruited from Bangor University School of Psychology student

22 participant panel and took part for course credits and a $£ 3$ payment. Twenty-two individuals

23 were excluded because their BMIs were below 18.5, because they showed uniformly low

24 liking across all sweetness concentrations (with ratings below 0.2 out of 10) or because of 
missing questionnaire data. The final sample consisted of 121 participants $(M=21.31$, $S E=0.48)$, comprised of 60 females $(M=20.87, S E=0.42)$ and 61 males $(M=21.75, S E=0.86)$.

\section{Design}

5 As in Experiment 1, participants were randomised to one of three groups: positively-framed, 6 negatively-frames and control. The dependent variable was participants' sweetness and liking

7 ratings for five concentrations of sucrose-sweetened Cherry Kool-Aid ${ }^{\mathrm{TM}}$ solutions.

\section{$9 \quad$ Procedure}

10 As in Experiment 1, participants completed the (state) PANAS-S (Watson et al., 1988) and pre-induction $10 \mathrm{~cm}$ VAS ratings of hunger and thirst. The reward-uncertainty induction and control protocol remained as described in Experiment 1. Participants in the control group were informed their payment would include the baseline of $£ 3$ plus an extra windfall of $£ 7$. Each sample of the taste test consisted of $2 \mathrm{ml}$ of Kool-Aid with five sucrose molarities: $0.05,0.10$, 0.21, 0.42, and 0.83M (Weafer et al., 2014), served at room temperature (Bartoshuk et al., 1982). None of the participants had previously encountered Kool-Aid as a flavour or brand.

Since judgements of the sweetness and pleasantness of sucrose solutions can be contextdependent (Riskey et al., 1979), the five concentrations were presented once within each one of five blocks, according to a Latin Square that generated 25 samples in total. Participants tasted and expectorated the samples, rinsing with water between each one. After each sample, participants completed VAS ratings of sweetness and liking (Weafer et al., 2014).

24 Following the sweetness taste test, but before the outcome of the die-roll was revealed, participants completed a further PANAS-S (Watson et al., 1988) and provided hunger and 
1 thirst (VAS) ratings. Participants also completed the AUDIT (Saunders et al., 1993) and

2 Beck's Depression Inventory (BDI-II) (Beck et al., 1996) to capture recent depressive

\section{$6 \quad$ Results}

\section{Group/sub-group selection and matching}

8 As in Experiment 1, we collapsed the positively-framed and the negatively-framed groups into 9 one reward-uncertain group. First, we considered the effects of reward uncertainty in the entire unselected sample of participants. There was some evidence of the predicted concentration-dependent increases in both sweetness (see Supplemental Material H Figure S8) and liking ratings in the reward-uncertain compared with the control participants (see Supplemental Material H Figure S9). However, these effects were not statistically significant $\left(\chi^{2}(1)=1.9504 ; \mathrm{p}=0.1625\right)$ and $\chi^{2}(1)=2.3593 ; \mathrm{p}=0.1245$, respectively; see Supplemental Materials $\mathrm{H}$ for details). Therefore, we focused on the sweet-likers in the remaining analysis.

Samples of both non-clinical and clinical participants can show heterogenous

hedonic/pleasantness responses to sweet tastes; with some individuals showing monotonic increases in liking across higher concentrations of sucrose solutions (and preferences for the strongest concentrations) but other individuals showing declining liking ratings beyond the lower concentrations (Asao et al., 2015; Kim et al., 2014; Moskowitz, 1971; Moskowitz et al., 1974; Pangborn, 1970). We see the same variability in our sample's liking ratings.

Here, we specified sweet-likers as those participants whose maximal liking ratings aligned with the $0.83 \mathrm{M}$ or $0.42 \mathrm{M}$ concentrations. This identified 107 participants. Consistent with 
1 previous reports (Asao et al., 2015; Kim et al., 2014; Moskowitz, 1971; Moskowitz et al.,

2 1974; Pangborn, 1970), at a group-level, these participants showed monotonic increases in

3 liking across the concentrations of sucrose solution whereas the 14 remaining participants

4 reported reduced liking beyond the $0.21 \mathrm{M}$ concentration (see Supplemental Materials $\mathrm{H}$

5 Figure S10). Since inclusion of these 14 participants - whose liking ratings depart markedly

6 from the modal pattern with sucrose molarities seen in our sample and whose maximal liking

7 ratings, as an index of participants' preferences, fell at lower concentrations - introduce

8 significant heterogeneity into the dataset, we confined our analysis to the 107 sweet-likers.

9

10 Among sweet-likers, the reward-uncertain and the control participants were matched for

gender (M:F; $18: 18$ vs 35:36; $\left.\chi^{2}(1)=0, p=1\right)$, age $(20.8 \pm .40$ vs $21.8 \pm 1.06 ; \beta=-0.919 ; p=0.332)$,

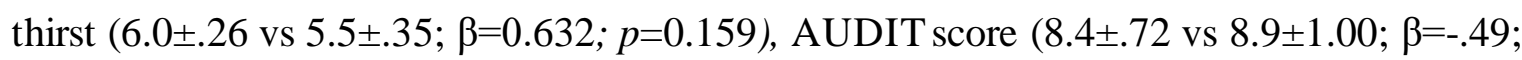
$p=0.69)$; state positive affect (28.7 \pm .74 vs $28.2 \pm 1.04 ; \beta=0.594 ; p=0.644)$ and negative affect (12.4 \pm .31 vs $12.1 \pm .41 ; \beta=0.297 ; p=0.577)$. However, the reward-uncertain group were somewhat more hungry than the control group $(4.3 \pm .33$ vs $2.9 \pm .35 ; \beta=1.411 ; p=0.0085)$ (see Supplemental Materials D/Table S2 for further psychometric details).

\section{Sweetness and Liking ratings}

Sweetness and liking ratings were analysed with hierarchical mixed-effects (maximum random-slope) models, tested with likelihood-ratio tests for the additional variance explained while minimising Type 1 errors (Barr, 2013). (See Supplemental Materials H/Statistical Approach.) Using R's lmer syntax, our base model, Model 1, took the form: Sweetness (or Liking $)=$ Reward Uncertainty + Molarity $+(1+$ Molarity $\mid$ Participant / Block $)$ while a second model, Model 2, added the interaction between reward uncertainty and molarity: 
1 Sweetness $($ or Liking $)=($ Reward Uncertainty * Molarity $)+$ Reward Uncertainty + Molarity +

2 (1 + Molarity | Participant / Block). Figure 3(left) illustrates the results for the sweet-likers.

$4 \quad$ Adding the interaction between reward uncertainty and molarity to Model 2 explained

5 significantly more variance $\left(\chi^{2}(1)=4.1946, p=0.04\right)$. Sweetness ratings of the reward uncertain

6 participants increased more steeply as a function of sucrose solution molarity than those of the

7 control participants. Figure 3(right) shows the effects of reward uncertainty on participants'

8 liking ratings of the same sucrose solution concentrations. Again, a likelihood-ratio test of the

9 comparison between Model 1 and 2 shows that the interaction between reward uncertainty and molarity again explained more variance $\left(\chi^{2}(1)=3.74, p=0.05\right)$. Specifically, the rewarduncertain participants' liking of sucrose solution concentrations increased at a steeper gradient compared with those of the controls. (Further, adding baseline thirst and hunger ratings to the models produced no marked changes in the variance explained by adding the interaction between reward uncertainty and molarity; Supplemental Materials $\mathrm{H}$ for details).
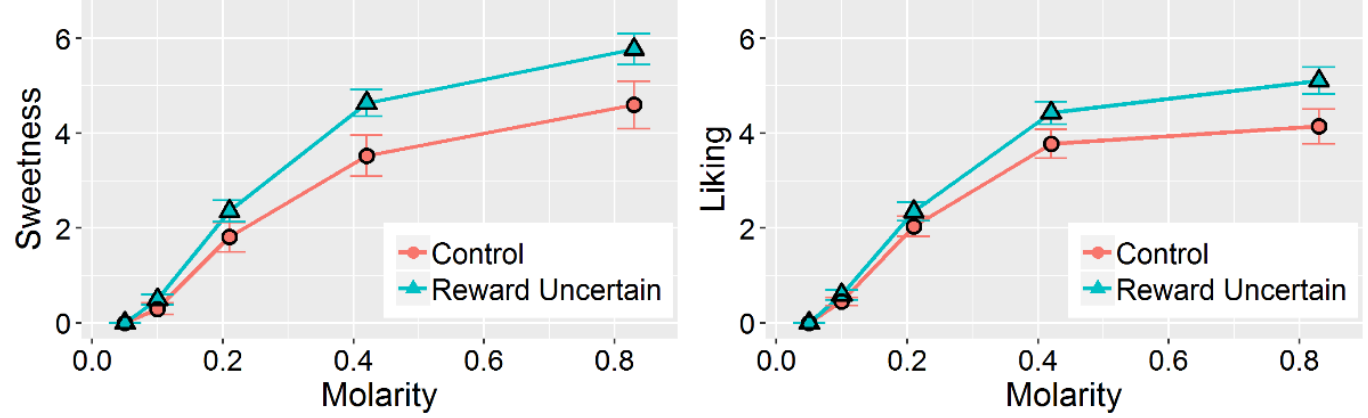

Figure 3 Average sweetness (left) and liking (right) ratings by molarity and group, normalized against the least sweet mixture. For each individual, the rating for a given molarity was calculated by taking their average rating across all five blocks and subtracting it against the average rating at $0.05 \mathrm{M}$. Error bars represent standard errors.

Finally, we tested whether the effects of reward uncertainty on participants' responses to sweetness were moderated by recent depressive symptoms measured with BDI-II (Beck et al., 1996). First, we calculated the average sweetness ratings for each participant across all 
concentrations and blocks, then normalized the ratings to a mean of zero and a standard

2 deviation of one. Next, we ran a linear regression model, boot-strapped 1,000 times, with the

3 form: Sweetness = Reward Uncertainty + BDI + Reward Uncertainty * BDI.

5 Sweetness ratings tended to decrease with increasing BDI scores amongst the control

6 participants but tended to increase slightly with BDI scores amongst the reward-uncertain

7 participants, reflected in the significant 2-way interaction between Reward Uncertainty and

8 BDI $(\beta=0.0718 ; 95 \%$ CI $[0.0029,0.1541])$. (See Supplemental Material I Figure S9).

\section{Discussion}

11 Experiment 3 investigated the hypothesis that reward uncertainty, as a state of not- knowing 12 about the outcome of a high-value monetary prospect, modulates the experience of other 13 palatable rewards; in this instance, expressed in the rated sweetness and liking of increasing concentrations of sucrose solutions (Lenoir et al., 2007; Moskowitz et al., 1974; Pfaffmann, 1980; van Opstal et al., 2020). Among the sample who reported preferences for the strongest concentrations of sucrose solutions - 'sweet-likers' - we find that incidental reward uncertainty for money increases the rated intensity and rated liking of sweet tastes. That these increases were concentration-dependent rules out the possibility that they reflect a generalised shift in the reward-uncertain participants' response biases (Moskowitz, 1971; Moskowitz et al., 1974; Pangborn, 1970; Riskey et al., 1979). Rather they suggest that, in some individuals, states of not-knowing enhance the reward experience of high-intensity sweet tastes.

Further, consumption of alcohol, food as well as drugs and gambling products are often motivated as ways to alleviate stress, anxiety or low mood (Boden \& Fergusson, 2011; Konttinen et al., 2019; Lloyd et al., 2010). The observation here that sweetness ratings were 
moderated differently by the depression symptoms (scored over 14days with the BDI-II)(Beck

2 et al., 1996) of the reward-uncertain participants compared with the control participants

3 provides an initial indication that effects of incidental reward uncertainty for one kind of

4 reward on the experience of other palatable directly-consumable rewards are mood-dependent.

6 Individuals tend to show heterogenous responses to sweet tastes (Asao et al., 2015; Kim et al.,

7 2014; Moskowitz, 1971; Moskowitz et al., 1974; Pangborn, 1970). In this experiment,

8 inclusion of the small number of participants with diminished hedonic responses to stronger

9 sucrose solutions weakened the above patterns, suggesting a lack of power to demonstrate a

general effect. So, in Experiment 4, we seek to replicate the impacts of incidental reward

uncertainty, this time, with a broader set of food and drink rewards and to test their associations with cognitive and affective risk factors for consumption-related health problems.

\section{Experiment 4}

Experiment 1 showed that incidental reward uncertainty can increase consumption of alcoholic drinks and palatable snacks while Experiment 3 demonstrated that reward uncertainty can increase the intensity of palatable reward experiences. Our final experiment in this series had two objectives. First, we sought to replicate the effects of Experiments 1 and 3 by testing whether reward uncertainty increases individuals' consumption and their responses to the taste experiences of a broadened range of palatable food and drink rewards (again presented in a fictive 'consumer taste test'). Second, we assessed whether the effects of reward uncertainty on responses to the taste characteristics and palatability of food and drink rewards are associated with inter-individual variation in cognitive and affective variables (including self-reported depressive symptoms) linked to unhealthy consumption behaviours. 
1 In addition to elevated rates of delay and probability discounting (Amlung et al., 2017;

2 Barlow et al., 2016; Bickel et al., 2014; Fields et al., 2013; Hendrickson \& Rasmussen, 2013;

3 Manwaring et al., 2011; Odum, 2011; Petry, 2001; Rasmussen et al., 2010; Stojek \&

4 MacKillop, 2017), hazardous consumption has been linked to variation in motor inhibition or

5 response-cancellation (Bartholdy et al., 2016; Billieux et al., 2010; de Ruiter et al., 2012;

6 Lawrence et al., 2015; Nederkoorn et al., 2010) and reflection impulsivity as the tendency to

7 initiate action at the expense of information sampling (Banca et al., 2015; Clark et al., 2006).

8 These findings raise the possibility that the effects of reward uncertainty on consumption (in

9 Experiment 1) and reward experiences (in Experiment 3) reflect variability in these functions.

11 Therefore, prior to the reward uncertainty induction of Experiment 4, we invited participants

to complete: (i) a standard stop-signal reaction time task (SSRT) as a measure of motor inhibition (Verbruggen et al., 2012); (ii) the $\mathrm{ED}_{50}$ and $\mathrm{EP}_{50}$ elicitations of delay and probability discounting (Cox \& Dallery, 2016; Koffarnus \& Bickel, 2014); and (iii) an explore/exploit choice task in an information sampling context as reflection impulsivity (Navarro et al., 2016; Tversky \& Edwards, 1966). We tested the prediction that the effects of reward uncertainty on responses to the taste properties of food and drink rewards are moderated by inter-individual variation in response control, discounting rates, and the balance between exploration versus exploitation in information-sampling.

Additionally, in a post-hoc test, Experiment 3 showed that, while sweetness intensity ratings diminished with more severe self-reported depression symptoms in the control participants, this trend was gently reversed in the reward uncertain participants. This suggests that the effects of reward uncertainty to enhance individuals' responses to food and drink rewards are mood-dependent. Studies of disrupted intensity and pleasantness ratings of sweet tastes in 
1 individuals with depressed mood show inconsistent results, probably reflecting small sample

2 sizes, differences in selection criteria (e.g. clinical vs community samples) and failures to test

against varying sucrose concentrations (Amsterdam et al., 1987; Dichter et al., 2010; Platte et al., 2013; Scinska et al., 2004; Steiner et al., 1969). In Experiment 4, therefore, we sought to replicate Experiment 3's moderation of reward uncertainty's effects on taste experiences by recent symptoms of depression, scored with the BDI-II (Beck et al., 1996).

Lastly, appraisal of probabilistic risk involves affective reactions about valanced outcomes (Lowenstein et al., 2001; Slovic et al., 2005). Other data suggest that increased intensity of sweet (and sometimes decreased intensity of sour) tastes can be linked to fluctuating positive affect triggered by successful outcomes (Noel \& Dando, 2015) or the concurrent presentation of positively-valenced visual stimuli (Wang \& Spence, 2018). In the online Experiments 2a and $2 \mathrm{~b}$, we found that the reward-uncertainty induction left participants less happy compared with the control procedure involving an equivalent-value windfall (see Supplemental Material F for details). However, neither Experiment $2 \mathrm{a}$ or $2 \mathrm{~b}$ involved any direct encounter with consumable food and drink rewards, precluding any test of whether the impacts of reward uncertainty on consummatory behaviours or related reward experiences are moderated by positive affect. So, to test this in the lab-setting of Experiment 4, we collected self-reported momentary happiness ratings before the reward-uncertainty inductions and afterwards.

\section{Methods}

Experiment 4 was approved by Bangor University (School of Psychology) Ethics Committee. All participants provided written, informed consent. 


\section{Participants}

2 Power analysis of Experiment 1 found that 135 participants are required to find a difference in snack consumption with $80 \%$ power (at $95 \%$ confidence)(see Supplemental Material G), 154

4 young adults (80 females) were recruited from Bangor University's School of Psychology

5 student panel and took part in exchange for course credits and a $£ 3$ payment. Twenty-two

6 participants were excluded for self-reported eating problems, food allergies, or on-the-day

7 technical difficulties with the protocol. The final sample included 132 participants $(M=21.05$,

$8 S E=0.30)$, comprised of 63 males $(M=21.94, S E=0.54)$ and 69 females $(M=20.24, S E=0.26)$.

\section{Design}

Like, Experiments 1 and 3, Experiment 4 consisted of a between-subject design in which participants were randomised to one of three groups: positively-framed; negatively-framed and control. Each participant group included 21 males and 23 females.

\section{Self-report questionnaires}

Participants completed the following set of psychometric questionnaires to match for alcohol and nicotine use: (i) the Alcohol Use Disorders Identification Test (AUDIT)(Saunders et al., 1993); (ii) the Fagerstrom Test for Nicotine Dependence (FTND) (Heatherton, 1991); and (iii) the Penn State Electronic Cigarette Dependence Index (PSECDI)(Foulds et al., 2014).

\section{Consumer evaluation ratings}

Participants also provided ratings of momentary hunger, thirst and happiness, as well as momentary ratings of how much they wanted to eat and how much they liked the different foods and drinks using $10 \mathrm{~cm}$ VAS with anchor points of 'Not at all' and 'Very Much'. 


\section{Cognitive assessments}

2 Participants completed: (i) a standard stop-signal reaction time task (SSRT) using the STOP-

3 IT computer program as a measure of motor inhibition (Verbruggen et al., 2012); (ii) the 5-

4 item $\mathrm{ED}_{50}$ and $\mathrm{EP}_{50}$ delay discounting and probability discounting elicitations (Cox \& Dallery,

5 2016; Koffarnus \& Bickel, 2014) and (iii) the Observe-or-Bet assessment of explore/exploit in

6 information sampling (Navarro et al., 2016). (See Supplementary Materials J for descriptions.)

7

\section{$8 \quad$ Procedure}

9 Upon arrival, participants were told they were going to complete a consumer evaluation of some food and drink products. First, they provided demographic information and completed baseline VAS ratings of their momentary hunger, thirst, and happiness. Next, participants completed the $\mathrm{ED}_{50}$ and $\mathrm{EP}_{50}$ assessments of delay and probability discounting rates (Cox \& Dallery, 2016; Koffarnus \& Bickel, 2014), the Observe-or-Bet assessment of explore/exploit in information sampling (Navarro et al., 2016), and the stop-signal reaction time task (SSRT) using the STOP-IT computer software (Verbruggen et al., 2012). Assessments were ordered to minimise proactive interference across the Observe-or-Bet, STOP-IT and ED50 and EP50 discounting assessments (Stevens et al., 2015; Verbruggen et al., 2012) (see Supplementary Materials $\mathrm{J}$ for detailed descriptions). Following completion of these cognitive assessments, participants provided pre-induction ratings of hunger, thirst and happiness.

Next, the reward-uncertainty induction was carried out exactly as described in Experiment 1 and 3. Participants in the positively- and negatively-framed groups were informed that their payment for taking part might be as much as $£ 24$ and rolled a die to be revealed at the end of the experiment. The control group was told they would receive a $£ 7$ bonus. All participants then completed a final set of post-induction VAS hunger, thirst and happiness ratings. 
1 Finally, participants completed the consumer evaluation test while watching a 10-minute

2 segment of the Simpsons. Hula Hoops ${ }^{\mathrm{TM}}$ and servings of fresh warm (and scented) sweet

3 popcorn, salty popcorn and sweet and salty popcorn were presented in bowls. First,

4 participants rated how much they wanted to eat and liked the food rewards (as a set) $(10 \mathrm{~cm}$

$5 \quad$ VAS with 'Not at all' and 'Very Much' as anchor points). Next, they tasted each individual

6 food reward and rated its visual appeal, how much they wanted to eat it, how much they liked

7 it, its sweetness, its saltiness and its taste intensity using a 1-5 Likert scale. At this point, the

8 experimenter placed three drinks (Coke-Cola ${ }^{\mathrm{TM}}$, Capri-sun ${ }^{\mathrm{TM}}$, and 7-up $\left.{ }^{\mathrm{TM}}\right)$ in front of the

9 participants and asked them to help themselves. During the evaluation period, the researcher

10 left the room and returned after 10min. Participants provided ratings for all food rewards and

11 for the drinks that they sampled. At the end of the television segment, the food rewards and

12 drinks were cleared. At this point, the outcome of the die-roll was revealed, and participants

13 were paid. Finally, participants completed the AUDIT (Saunders et al., 1993), BDI-II (Beck et

14 al., 1996), FTND (Heatherton, 1991) and PSECDI (Foulds et al., 2014) and were discharged.

16 Results

\section{Group-matching}

18 As in Experiment 1 and 3, the positively-framed and negatively-framed groups did not differ markedly in their sensory ratings of the food rewards/snacks and drinks (see Supplementary

Materials $\mathrm{C}$ for details). Therefore, we collapsed these groups into one reward-uncertain group. Linear regressions showed that the reward-uncertain participants and control participants were well-matched for age $(21.3 \pm .40$ vs $20.7 \pm .41 ; \beta=-0.5818 ; p=0.364)$, depressive symptoms $(12.4 \pm 1.01$ vs $13.4 \pm 1.29 ; \beta=-1.068 ; p=0.531)$, hazardous drinking (7.74 \pm .61 vs $8.56 \pm .92 ; \beta=-0.829, p=0.447)$ and nicotine usage $(.65 \pm .17$ vs $.93 \pm .24 ; \beta=-0.284$; $p=0.343$ ) (see Supplementary Materials D/Table S3 for further details). Just-prior to the 
reward-uncertainty induction, the reward-uncertain participants and the control participants were matched in terms of state hunger $(4.15 \pm .28$ vs $3.93 \pm .45 ; \beta=0.216 ; p=0.67)$ and thirst $(5.15 \pm .22$ vs $5.18 \pm .35 ; \beta=0.216 ; p=0.67)$. They were also matched in terms of their preinduction momentary happiness $(5.84 \pm 0.25$ vs $5.53 \pm 0.19 ; \beta=-0.307 ; p=0.352)$.

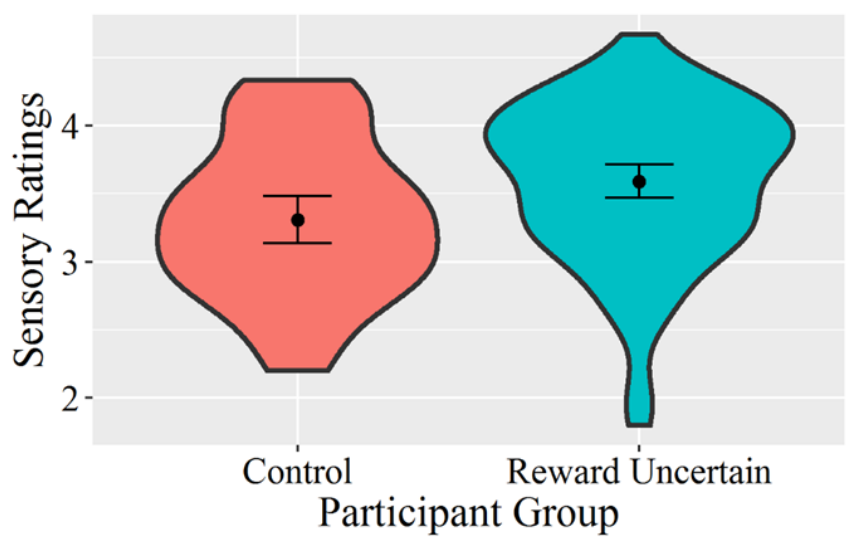

Figure 4 Taste intensity ratings by the reward-uncertain and control groups in Experiment 4, calculated as the average of individuals' saltiness rating for Hula Hoops ${ }^{\mathrm{TM}}$, salty popcorn and salty \& sweet popcorn and sweetness rating for sweet popcorn, salty \& sweet popcorn, CokeCola $^{\mathrm{TM}}$, Capri-sun ${ }^{\mathrm{TM}}$, and 7-up ${ }^{\mathrm{TM}}$. Error bars represents $95 \%$ confidence intervals.

\section{Taste intensity and liking ratings}

Experiment 4 was intended to assess whether, as in Experiment 3, reward uncertainty was associated with changes in individuals' experience of palatable foods and drink rewards. To test this, we focused on each participant's average saltiness rating for salty snacks (salty popcorn, and salty and sweet popcorn and Hula Hoops ${ }^{\mathrm{TM}}$ ), combined with the average sweetness rating for sweet snacks and drinks (sweet popcorn, salty and sweet popcorn, Coke Cola $^{\mathrm{TM}}$, Capri-Sun ${ }^{\mathrm{TM}}$, and 7 -up ${ }^{\mathrm{TM}}$ ). Figure 4 illustrates the results. We ran a linear model of the form: Sensory ratings $=$ Gender + Reward Uncertainty, boot-strapped 1,000 times.

Reward uncertainty produced substantial increases in participants' rated sweetness and saltiness of the food and drink rewards $(3.59 \pm .061$ vs $3.31 \pm .085, \beta=0.281 ; 95 \%$ CI $[0.086$, 
$10.486])$. Additional boot-strapped regressions showed that reward uncertainty increased

2 sweetness $(3.64 \pm .079$ vs $3.40 \pm .101, \beta=0.241 ; 95 \%$ CI $[0.002,0.515])$ and saltiness ratings

$3(3.52 \pm .075$ vs $3.21 \pm .110, \beta=0.303 ; 95 \%$ CI $[0.048,0.557])$ when considered on their own.

4

5 Next, we tested whether the effects of reward uncertainty on taste intensity ratings were

6 moderated by participants' stop-signal performance (SSRT), delay discounting rates (ED 50$)$,

7 probability discounting rates $\left(\mathrm{EP}_{50}\right)$, explore-exploit as information sampling (Observe-or-bet)

8 or recent depressive symptoms (BDI-II). We tested regressions with a boot-strapped model of

9 the form: Sensory ratings = Reward Uncertainty + IV + Reward Uncertainty * IV, where IV

10 (independent variable) represents each potential moderating variable.

12 Sensory ratings did not vary by stop-signal time (SSRT) $(\beta=0.0004 ; 95 \%$ CI $[-0.0021$, $130.0022]),(\log \mathrm{k})$ delay discounting rates $(\beta=0.0415 ; 95 \% \mathrm{CI}[-0.160,0.223])$, or $(\log \mathrm{h})$

14 probability discounting rates $(\beta=0.0077 ; 95 \%$ CI $[-0.1437,0.1573])$. Neither did sensory

15 ratings vary by participants' average decision-threshold in the Observe-Bet assessment $16 \quad(\beta=0.134 ; 95 \%$ CI $[-0.1347,0.2940])$. There was little indication that changes in participants'

17 sensory ratings under conditions of reward uncertainty compared with the control procedure were substantively moderated by participants' SSRT $(\beta=-0.001 ; 95 \%$ CI $[-0.0035,0.0016])$ or their $\mathrm{ED}_{50}$ and $\mathrm{EP}_{50}$ discounting rates $(\beta=-0.130 ; 95 \% \mathrm{CI}[-0.564,0.092])$ and $(\beta=-0.0336$; 95\% CI [-0.1961, 0.1181]). Associations between participants' sensory ratings and average decision-thresholds of the Observe-Bet assessment did vary somewhat between the rewarduncertain and control groups $(\beta=-0.288 ; 95 \%$ CI $[-0.5417,-0.0228])$. However, these differences were difficult to interpret; and they are not discussed further here. 
1 As in Experiment 3, ratings of sweetness and saltiness tended to diminish with depressive

2 symptoms among the control participants, (see Figure 5(left)) $(\beta-0.027 ; 95 \%$ CI [-0.0452, -

3 0.010]). However, this negative relationship was reversed in the reward-uncertain group,

4 reflected in the interaction between reward uncertainty and BDI-II scores $(\beta=0.041 ; 95 \% \mathrm{CI}$

5 [0.021, 0.064]). In the reward-uncertain group, those with the most depressive symptoms rated

6 the sweet and saltiness of the food and drinks as high or higher than others in their group.

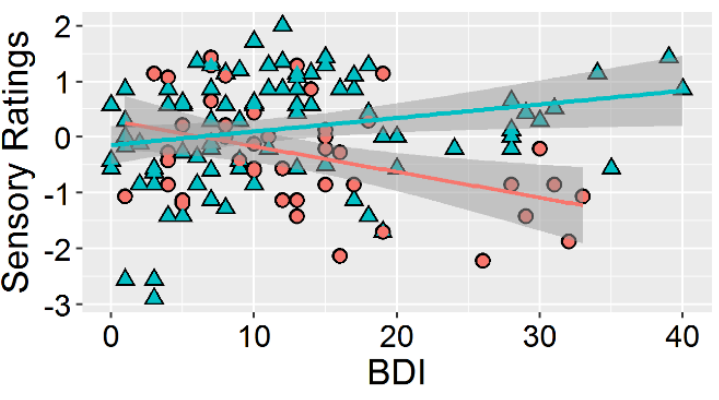

- Control $\Delta$ Reward Uncertain

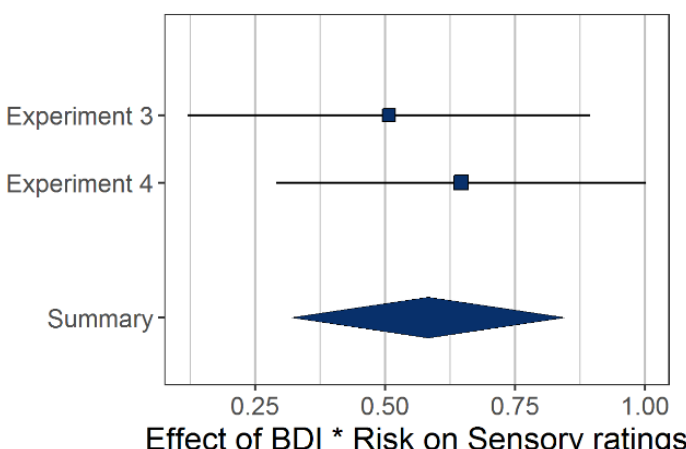

Effect of BDI * Risk on Sensory ratings
9

9

10

11

12

13

14

15

16

17

Figure 5 Left: Effect of reward uncertainty on sensory ratings and Beck's Depression Inventory (BDI-II)(Beck et al., 1996) in Experiment 4. Each line represents the best fit line within the reward uncertain (blue triangles) and control (red circles) groups. Grey areas represent $95 \%$ confidence bands for the regression. Right: Forest plot of the interaction effect between BDI-II and reward uncertainty on sensory ratings in Experiment 3 and 4.

Stand ardized beta values were used in the analysis. The summary diamond represents the estimated effect of the interaction. The 95\% CI's are depicted by the edge of the diamond.

1 Finally, we considered the moderated effects of recent depressive symptoms (BDI-II scores)

across Experiments 3 and 4. To do this, we normalized participants' average sweetness ratings (in Experiment 3), average sweet and saltiness ratings (in Experiment 4), and BDI-II scores to a mean of zero and a standard deviation of one. For each experiment, we then ran a bootstrapped regression, with 1,000 runs, of the form: Sensory ratings $=$ Reward Uncertainty + BDI + Reward Uncertainty * BDI. Using stand ardized $\beta$-values with identical multiple regression models (Becker \& Wu, 2007), we produced a forest plot in Figure 5(right). Across 
1 Experiment 3 and 4, the impact of reward uncertainty on taste intensity ratings were clearly

2 moderated by depressed mood (See Supplementary Material I and Figure S10 for details.)

$4 \quad$ Wanting, liking and shifts in momentary happiness

5 Boot-strapped regressions showed that the reward uncertainty induction produced modest, but

6 again not quite significant, increases in how much participants wanted to consume the food

7 and drink rewards compared with the control (windfall) procedure (3.002 $\pm 0.092 \mathrm{vs}$

$82.756 \pm 0.119 ; \beta=0.2472 ; 95 \%$ CI $[-0.08,0.54])$. Liking ratings were comparable between the

9 two groups $(3.377 \pm 0.630$ vs $3.260 \pm 0.074 ; \beta=0.117 ; 95 \%$ CI $[-0.09,0.29])$.

11 For momentary happiness, a $2 \times 2$ analysis of variance with the between-subjects factor of

12 Group (reward-uncertain vs control) and the within-subjects factor of Time (pre- vs postinduction) showed that post-induction happiness ratings were increased slightly less in the reward-uncertain participants compared with the control participants $(0.68 \pm 0.15$ from $5.53 \pm 0.19$ compared with $0.96 \pm 0.19$ from $5.84 \pm 0.25)$. However, this difference was not statistically reliable as indicated by the 2-way interaction between Group and Time $(\mathrm{F}(1$, 257) $=0.296, p=0.587)$. Post-induction, the reward-uncertain participants reported being marginally less happy compared with the control participants but again not significantly so $(6.22 \pm 0.21$ vs $6.80 \pm 0.31, \mathrm{~F}(1,129)=2.405, \mathrm{p}=.123)$ (Supplemental Material F/Table 6).

Other data suggest that higher positive emotion can predict more intense sweetness ratings (Noel \& Dando, 2015). As such, despite only marginal differences in the happiness ratings of the groups, we tested whether post-induction happiness predicted sensory ratings. A model of the form: Sensory Ratings = Post-induction Happiness, boot-strapped 1,000 times, showed that taste intensity ratings were not associated with fluctuating momentary happiness $(\beta=-$ 
2 Post-induction Happiness, showed that the participants' increased taste intensity ratings

3 following the reward-uncertainty induction remained significant even when controlling for

4 post-induction momentary happiness $(\beta=0.281 ; 95 \%$ CI $[0.0667,0.4892])$

5

\section{Food and drink consumption}

7 Differences in the amounts of snacks and volume of drink consumed in the reward-uncertain

8 and control participants were not as strong as observed in Experiment 1. Consumption of the

9 Hula Hoops ${ }^{\mathrm{TM}}$, sweet popcorn, salty popcorn and sweet and salty popcorn were normalized as in Experiment 1; i.e. scaled by the average weight/amount consumed and calculated as the mean of all four foods consumed. Figure 6 illustrates the average food consumption by group. We ran a boot-strapped regression 1,000 times of the form: Snack Consumption $=$ Gender + Reward Uncertainty. Whilst the reward-uncertain participants ate more than the control participants, as they had in Experiment 1, the 95\% confidence interval did not quite clear zero $(\beta=0.138 ; 95 \%$ CI $[-0.0466,0.3142])$ and there was no marked between-group difference in the volume of high-sugar drinks consumed $(\beta=-0.166 ; 95 \%$ CI $[-0.4806,0.1753])$.

Figure 6 Average snacks consumed by condition in Experiment 4. Consumption was calculated by normalizing the values of each of the four snacks and then taking an individual's average across all snacks. Error bars represent $95 \%$ confidence intervals. 
1 Finally, we checked whether consumption of palatable food and drink rewards reflected

2 participants' sensory ratings. We ran a linear model of the form: Consumption $=$ Gender +

3 Sensory Ratings, boot-strapped 1,000 times. This demonstrated a strong positive association

4 between participants' consumption and rated taste intensity of the sweet and saltiness of food

5 and drink rewards $(\beta=0.145 ; 95 \%$ CI $[0.0147,0.2706])$. So, whilst the effect of reward

6 uncertainty on consumption was not as marked as it had been in the bogus taste test of

7 Experiment 1, participants' consumption was positively correlated with their taste intensity

8 ratings, and these ratings were very substantively modulated by uncertainty.

10 Discussion

11 Experiment 4 intended to replicate the findings of Experiment 1 and 3; namely, that reward

12 uncertainty is associated with heightened consumption and responses to the taste characteristics of palatable food and drink rewards. The results show that reward-uncertain participants rated the sweet rewards as more intensely sweet compared with the control participants, and the salty rewards as saltier. These increases were substantive: $\sim 9 \%$ in rated sweetness and saltiness. However, and in contrast to Experiment 1, the reward-uncertain participants showed only a modest increase in the consumption of food snacks whose confidence intervals did not quite clear zero compared with the control participants; and no clear change in the volume of sugary drinks consumed. As in Experiment 2, the wanting ratings of the reward-uncertain participants tended to be increased compared with the controls but not quite significantly so; the liking ratings of the two groups were comparable.

Experiment 4 showed marginal increases in momentary happiness following both the rewarduncertainty induction and the control procedure involving the unexpected windfall of equivalent expected value. Other evidence links increased taste intensities of sweetness to 
1 enhanced positive affect triggered by probabilistic positive events (Noel \& Dando, 2015) or

2 the presentation of positively-valanced visual stimuli (Wang \& Spence, 2018). Here, in the

3 laboratory setting of Experiment 4, the increases in momentary happiness were no greater in

4 the reward-uncertain participants than in the control participants; if anything, they were

5 slightly, but non-significantly, reduced. Further taste intensity ratings were unrelated to post-

6 induction momentary happiness. Collectively, these data suggest that the effects of incidental

7 reward uncertainty about monetary outcomes on individuals' broader reward experiences do

8 not reflect fluctuations in momentary positive affect, at least when measured as happiness.

9

The effects of reward uncertainty on taste ratings were not markedly associated with variability of cognitive functions linked to unhealthy consumption: delay and probability discounting (Hendrickson \& Rasmussen, 2013; Rasmussen et al., 2010; Reynolds et al., 2004); motor inhibition and control (Bartholdy et al., 2016; Billieux et al., 2010; de Ruiter et al., 2012; Lawrence et al., 2015; Nederkoorn et al., 2010); and the balance between acting and information-gathering (Banca et al., 2015; Clark et al., 2006). However, these data replicate the finding of Experiment 3 that reward uncertainty reversed the tendency of taste experiences to be blunted in participants reporting more depressive symptoms compared with those reporting fewer symptoms (Amsterdam et al., 1987; Dichter et al., 2010; Platte et al., 2013; Scinska et al., 2004; Steiner et al., 1969). People can consume alcohol, drugs and food and gambling products to regulate anxiety, stress and low mood (Boden \& Fergusson, 2011; Konttinen et al., 2019; Lloyd et al., 2010). Together, Experiment 3 and Experiment 4 point to one candidate mediating mechanism; that reward-uncertainty experiences restore the normative experiences of other primary rewards in vulnerable individuals. 
2 Reward uncertainty prompts exploration and learning (Anselme \& Güntürkün, 2019; Caraco

3 et al., 1980; Ekman \& Hake, 1990) and strengthens approach behaviours (Anselme et al.,

4 2013; Gottlieb, 2004). In schedule-induced models, reward uncertainty in the form of

5 intermittent delivery of one reward can promote consumption of another reward as an

6 adjunctive behaviour (Cantor et al., 1982; Cherek, 1982; Falk, 1998; Falk et al., 1972; Falk \&

7 Tang, 1988; Samson \& Falk, 1974; Wilson \& Cantor, 1987). Reward uncertainty is

8 ubiquitous across gambling products (Ladouceur et al., 2003), marketing promotions (Kalra

$9 \quad \&$ Shi, 2010), gaming (Zendle et al., 2020) and gamification (Burke, 2016); often promoting

hedonic forms of consumption (Hirschman \& Holbrook, 1982; Milkman, 2012). In four experiments, we sought to identify whether incidental reward uncertainty - as states of 'notknowing' that exist between actions and positively-valanced monetary outcomes - enhance in-the-moment consumption and the experience of food and drink rewards.

Experiment 1 demonstrates that reward uncertainty - operationalised as a risk-based gamble with a $1 / 3$ probability of increasing participants' monetary fee by eight times its original value - can increase consumption of both branded alcoholic beer and palatable 'pub' snacks. Experiments $2 \mathrm{a}$ and $2 \mathrm{~b}$ show that these consummatory behaviours are unlikely to reflect gross changes in self-control as delay-dependent impulsivity or risk-tolerance linked to alcohol and unhealthy eating (Barlow et al., 2016; Bickel et al., 2014; Fields et al., 2013; Manwaring et al., 2011; Odum, 2011; Petry, 2001; Rasmussen et al., 2010; Reynolds et al., 2004; Stojek \& MacKillop, 2017). However, Experiments 3 and 4 show that reward uncertainty can heighten individuals' responses to the taste characteristics of palatable energy-dense food and drink rewards in ways that appear independent of inter-individual variability in delay and probability discounting rates, motor control and reflection impulsivity 
but appear strongest in individuals reporting depressed symptoms. Collectively, these data suggest a working hypothesis that reward uncertainty, as a state of 'not knowing', operate as a mood-dependent 'taste intensifier' of palatable rewards, potentially fuelling consumption.

5 Before discussing the significance of these findings, we consider some methodological and interpretive issues. First, the evaluation of probabilistic risk of the kind presented in the dieroll of these experiments depend, in part, upon affective reactions of expected outcomes

8 (Lowenstein et al., 2001; Slovic et al., 2005). Consistent with work on the savouring of anticipatory cognitive and affective states in risk-based scenarios (Ahlbrecht \& Weber, 1996; Loewenstein \& Elster, 1992; Lovallo \& Kahneman, 2000), we used a fully specified riskbased prospect - a fair 6-sided die roll - to induce reward uncertainty in comparison with a windfall equivalent to the prospect's expected value as a stringent control. These experiments provide preliminary information about the affective changes produced by reward uncertainty and their relationships with consumption and reward experiences. The online Experiments 2a and $2 \mathrm{~b}$ showed that post-induction, momentary happiness and alertness were lower in the reward-uncertain participants compared with the control participants (Supplemental Material F). However, the significance of these differences in relation to our main hypothesis is difficult to assess given the absence of opportunities to consume real food and drinks in those experiments. On the other hand, the laboratory-based Experiment 4 is more helpful. Other data indicate that the intensity of sweet tastes can be linked to increased positive affect elicited by successful outcomes (Noel \& Dando, 2015) or the presentation of positively-valanced external stimuli (Wang \& Spence, 2018). However, in Experiment 4, while sweetness and saltiness ratings were increased in the reward-uncertain compared with control participants, the post-induction increases in momentary happiness were, if anything, slightly reduced, as they were in Experiments $2 \mathrm{a}$ and $2 \mathrm{~b}$. This suggests that the effects of incidental reward 
uncertainty involving monetary outcomes on individuals' broader reward experiences do not

2 reflect associated fluctuations in momentary positive affect as happiness.

4 Second, Experiments $2 \mathrm{a}$ and $2 \mathrm{~b}$ tested the possibility that reward uncertainty promotes

5 alcohol and food consumption by transiently undermining self-control by increasing delay

6 discounting rates or by increasing probability discounting rates (Barlow et al., 2016; Petry,

7 2001; Rasmussen et al., 2010; Stojek \& MacKillop, 2017). While these experiments showed

8 no evidence of the gross changes in delay and probability discounting rates that are detectable

9 with hypothetical monetary rewards (Cox \& Dallery, 2016; Koffarnus \& Bickel, 2014), and

10 which could reflect the exhaustion of generalised self-control as a psychological 'muscle'

11 (Milkman, 2012), we acknowled ge that discounting of directly consumable rewards can be more rapid than for monetary rewards (Odum et al., 2006; Rasmussen et al., 2010). Thus, incidental reward uncertainty for money might still modulate the discounting of real foods and drinks that are available for consumption. However, Experiments $2 \mathrm{a}$ and $2 \mathrm{~b}$ demonstrate that such transient increases in impulsivity are likely be reward-and situation-specific.

17 Third, in Experiments 1, 3, and 4 we found that the positively-framed and the negativelyframed prospects did not generate substantial differences in consumption or responses to the taste characteristics of food and drink rewards. Framing effects can be ameliorated when outcomes are presented as fully specified risk-based gambles (Levin et al., 1998; Tversky \&

21 Kahneman, 1981). Our data suggest that the participants of the positively- and negativelyframed groups encoded the uncertainty in equivalent terms, or that reward uncertainty couched as gains and losses produce similar effects on consumption and reward experiences. 
1 Finally, in Experiment 1, we found substantive increases in the consumption of both alcohol

2 and pub snacks following the reward-uncertainty induction compared with the windfall of the

3 control procedure. However, in Experiment 4, the corresponding increases in the quantity of

4 palatable food and drinks consumed were only modest. Demonstrating changes in food and

5 drink intake in laboratory settings following dietary or situational manipulations can be

6 challenging (Blundell et al., 2009), reflecting motivational factors (hunger, thirst or protocol

7 instructions) and situational factors (experimenter and participant characteristics, sex

8 differences as well as audience effects) (Robinson et al., 2017; Robinson et al., 2014). We do,

9 however, know that taste intensities gathered through the taste-and-swallow protocols used in

10 Experiment 4 are positively associated with ad libitum consumption (Zand stra et al., 1999).

11 Other data indicate that, up to 'ideal' values of sweetness and saltiness, increased taste intensities are associated with increased food intake and deferred satiation (Geiselman et al., 1998). Consistent with this, Experiment 4 showed that participants' increased sweetness and saltiness ratings predicted increased intake in the consumer taste test, suggesting that experiences of reward uncertainty may facilitate broader consummatory behaviours.

\section{Rewards, uncertainty and consumption.}

In animals, training with intermittent Pavlovian or operant conditioning preparations engages dopaminergic learning mechanisms that track signals with incentive salience, code risk and discrepancies between expected and delivered outcomes (Anselme et al., 2013; Falk et al., 1972; Fiorillo et al., 2003; Schultz et al., 2008). Exposure to reward uncertainty in these forms can also increase risky choices for higher value rewards (Zeeb et al., 2017) and increase behavioural responses to amphetamine administration, consistent with the sensitisation of dopamine circuits (Robinson et al., 2015; Zack et al., 2014; Zeeb et al., 2017). Here, incidental reward uncertainty, as states of 'not-knowing', produced only modest 
1 increases in the self-reported wanting of food rewards in Experiment 1 and Experiment 4.

2 Possibly, reward uncertainty alters implicit measures of wanting processes (Tibboel et al.,

3 2015). However, the absence of substantive changes in wanting under conditions of reward-

4 uncertainty about monetary outcomes in these experiments suggests limited motivational

5 transfer to the specific food and drink consumable rewards. Rather it suggests broader

6 processes of activation (Roper, 1981), savouring or anticipatory utility (Ahlbrecht \& Weber,

7 1996; Lovallo \& Kahneman, 2000; Ruan et al., 2018); or perhaps 'incentive hope' as

8 motivational excitement about future possible good outcomes (Anselme \& Güntürkün, 2019).

10 Finally, anhedonia is a central feature of individuals' experience of depression (Pelizza \&

11 Ferrari, 2009). Experiment 3 and 4 showed that reward uncertainty reversed the tendency of

12 taste experiences to be blunted in participants reporting more depressive symptoms, as scored

13 with the BDI-II (Beck et al., 1996), compared with participants reporting fewer symptoms.

14 Individuals with depression can show altered responses to sweet taste intensities (Amsterdam

15 et al., 1987; Platte et al., 2013; Steiner et al., 1969) that can be moderated by age (as

16 sensitivity declines) (Hur et al., 2018), outcome measure (Steiner et al., 1993) and reflect

17 response biases (Potts et al., 1997). That the effects of reward uncertainty were more closely

18 linked to recent depressive symptoms than individual variation in delay or probability

19 discounting, motor control and reflection impulsivity suggests a mood-dependent rather than

20 cognitive locus of action. Still other evidence indicates that individuals with gambling

21 problems are motivated to gamble by its capacity to modulate anxious and depressed mood

22 (Blaszczynski \& Nower, 2002). Possibly, the reward uncertain experiences of gambling

23 products lift mood by intensifying or restoring access to other, broader reward experiences. 
1 Notwithstanding these possibilities, our findings are the first to show that incidental reward

2 uncertainty about one significant reward - money - can intensify the experience of other

3 rewards in a mood-dependent manner, sometimes promoting in-the-moment consumption.

4

6 To our knowledge, this is the first investigation of how uncertainty about one reward can

7 influence the consumption and experience of other rewards in humans. The impetus for these

8 experiments was our laboratory's preoccupation with the co-occurrence of gambling harms

9 and problematic relationships with other rewards (e.g. alcohol, drugs, etc). While the adverse

10 health outcomes of these associations undoubtedly reflect social and health inequalities, we

11 wondered whether there might be situational factors that promote in-the-moment co-

12 consumption of multiple rewards. In particular, we wondered whether there is something

13 special about the reward uncertainty engineered into commercial gambling products, gaming and marketing promotions. As ever in psychology, these first experiments opened an expanded array of intriguing avenues. We assume that, depending upon circumstance and individual, uncertainty about one reward can trigger a complex of cognitive and affective processes that interactively modulate other reward-related experiences. The active 'ingredients' within these processes may include, but are not limited to, expectancy or anticipation of valanced events, motor activation, priming of error-correction learning, attentional processing of signals with incentive-salience, and affective forecasting and reactions to risk. Exploring the functional impacts of incidental uncertainty could help to understand the interface between addictions, emotional disorders and consumerism. 


\section{Acknowledgements}

2 The authors would like to thank Rachel Newey for comments on an earlier version of this 3 manuscript.

4

5

\section{Disclosures}

6 This research was own a/c funded.

7

8 
Achananuparp, P., Lim, E.-P., Abhishek, V., \& Yun, T. (2018). Eat \& tell: A randomized trial of randomloss incentive to increase dietary self-tracking compliance. Proceedings of the 2018 International Conference on Digital Health,

Ahlbrecht, M., \& Weber, M. (1996). The resolution of uncertainty: An experimental study. Journal of Institutionaland Theoretical Economics (JITE)/Zeitschrift fürdie gesamte Staatswissenschaft, 593-607.

Amlung, M., Vedelago, L., Acker, J., Balodis, I., \& Mackillop, J. (2017). Steep delay discounting and addictive behavior: A meta-analysis of continuous associations. Addiction, 112(1), 51-62.

Amsterdam, J. D., Settle, R. G., Doty, R. L., Abelman, E., \& Winokur, A. (1987). Taste and smell perception in depression. Biological psychiatry, 22(12), 1481-1485.

Anselme, P., \& Güntürkün, O. (2019). How foraging works: uncertainty magnifies food-seeking motivation. Behavioral and Brain Sciences, 42.

Anselme, P., Robinson, M. J., \& Berridge, K. C. (2013). Reward uncertainty enhances incentive salience attribution as sign-tracking. Behavioural brain research, 238, 53-61.

Asao, K., Miller, J., Arcori, L., Lumeng, J. C., Han-Markey, T., \& Herman, W. H. (2015). Patterns of sweet taste liking: A pilot study. Nutrients, 7(9), 7298-7311.

Banca, P., Lange, I., Worbe, Y., Howell, N. A., Irvine, M., Harrison, N. A., Moutoussis, M., \& Voon, V. (2015, Feb 11). Reflection impulsivity in binge drinking: behavioural and volumetric correlates. Addict Biol. http://www.ncbi.nlm.nih.gov/pubmed/25678093

Bar-Anan, Y., Wilson, T. D., \& Gilbert, D. T. (2009). The feeling of uncertainty intensifies affective reactions. Emotion, 9(1), 123.

Barlow, P., Reeves, A., McKee, M., Galea, G., \& Stuckler, D. (2016). Unhealthy diets, obesity and time discounting: a systematic literature review and network analysis. obesity reviews, 17(9), 810819.

Barr, D. J. (2013). Random effects structure for testing interactions in linear mixed-effects models. Frontiers in psychology, 4, 328.

Bartholdy, S., Dalton, B., O’Daly, O. G., Campbell, I. C., \& Schmidt, U. (2016). A systematic review of the relationship between eating, weight and inhibitory control using the stop signal task. Neuroscience \& Biobehavioral Reviews, 64, 35-62. 
Bartoshuk, L., Rennert, K., Rodin, J., \& Stevens, J. (1982). Effects of temperature on the perceived sweetness of sucrose. PhysiolBehav, 28(5), 905-910.

Beck, A. T., Steer, R. A., \& Brown, G. K. (1996). Manualforthe Beck Depression Inventory-II. Psychological Corporation.

Becker, B. J., \& Wu, M.-J. (2007). The synthesis of regression slopes in meta-analysis. Statistical science, 22(3), 414-429.

Bellis, M. A., Hughes, K., Nicholls, J., Sheron, N., Gilmore, I., \& Jones, L. (2016). The alcohol harm paradox: using a national survey to explore how alcohol may disproportionately impact health in deprived individuals. BMC public health, 16(1), 111.

Berry, M. S., Sweeney, M. M., Morath, J., Odum, A. L., \& Jordan, K. E. (2014). The nature of impulsivity: Visual exposure to natural environments decreases impulsive decision-making in a delay discounting task. PLoS One, 9(5), e97915.

Bickel, W. K., Wilson, A. G., Franck, C. T., Mueller, E. T., Jarmolowicz, D. P., Koffarnus, M. N., \& Fede, S. J. (2014). Using crowdsourcing to compare temporal, social temporal, and probability discounting among obese and non-obese individuals. Appetite, 75, 82-89.

Billieux, J., Gay, P., Rochat, L., Khazaal, Y., Zullino, D., \& Van der Linden, M. (2010). Lack of inhibitory control predicts cigarette smoking dependence: evidence from a non-deprived sample of light to moderate smokers. Drug Alcohol Depend, 112(1-2), 164-167.

Blaszczynski, A., \& Nower, L. (2002, May). A pathways model of problem and pathological gambling. Addiction, 97(5), 487-499. http://www.ncbi.nIm.nih.gov/entrez/query.fcgi?cmd=Retrieve\&db=PubMed\&dopt=Citation \&list uids $=12033650$

Blundell, J. E., De Graaf, K., Finlayson, G., Halford, J. C., Hetherington, M., King, N., \& Stubbs, J. (2009). Measuring food intake, hunger, satiety and satiation in the laboratory. Handbook of assessment methods for eating behaviours and weight-related problems: Measures, theory and research. 2nd ed. Newbury Park, CA: Sage, 283-325.

Bobo, J. K., \& Husten, C. (2000). Sociocultural influences on smoking and drinking. Alcohol Research and Health, 24(4), 225-232.

Boden, J. M., \& Fergusson, D. M. (2011). Alcohol and depression. Addiction, 106(5), 906-914.

Burke, B. (2016). Gamify: How gamification motivates people to do extraordinary things. Routledge.

Cantor, M. B., Smith, S. E., \& Bryan, B. R. (1982). Induced bad habits: Adjunctive ingestion and grooming in human subjects. Appetite, 3(1), 1-12. 
Caraco, T., Martindale, S., \& Whittam, T. S. (1980). An empirical demonstration of risk-sensitive foraging preferences. Animal Behaviour, 28(3), 820-830.

Casperson, S. L., Lanza, L., Albajri, E., \& Nasser, J. A. (2019). Increasing chocolate's sugar content enhances its psychoactive effects and intake. Nutrients, 11(3), 596.

Cherek, D. (1982). Schedule-induced cigarette self-administration. Pharmacology Biochemistry and Behavior, 17(3), 523-527.

Clark, L., Robbins, T. W., Ersche, K. D., \& Sahakian, B. J. (2006, Sep 1). Reflection impulsivity in current and former substance users. Biol Psychiatry, 60(5), 515-522. http://www.ncbi.nlm.nih.gov/entrez/query.fcgi?cmd=Retrieve\&db=PubMed\&dopt=Citation \&list_uids $=16448627$

Corwin, R. L. (2011). The face of uncertainty eats. Current Drug Abuse Reviews, 4(3), 174-181.

Cox, D. J., \& Dallery, J. (2016). Effects of delay and probability combinations on discounting in humans. Behavioural Processes, 131, 15-23.

Cronce, J. M., \& Corbin, W. R. (2010). Effects of alcohol and initial gambling outcomes on withinsession gambling behavior. Experimental and Clinical Psychopharmacology, 18(2), 145.

Daniel, T. O., Said, M., Stanton, C. M., \& Epstein, L. H. (2015). Episodic future thinking reduces delay discounting and energy intake in children. Eating Behaviors, 18, 20-24.

Daniel, T. O., Stanton, C. M., \& Epstein, L. H. (2013, Dec). The future is now: comparing the effect of episodic future thinking on impulsivity in lean and obese individuals. Appetite, 71, 120-125. http://www.ncbi.nlm.nih.gov/pubmed/23917063

de Ruiter, M. B., Oosterlaan, J., Veltman, D. J., van den Brink, W., \& Goudriaan, A. E. (2012). Similar hyporesponsiveness of the dorsomedial prefrontal cortex in problem gamblers and heavy smokers during an inhibitory control task. Drug AlcoholDepend, 121(1-2), 81-89.

DelVecchio, D., Henard, D. H., \& Freling, T. H. (2006). The effect of sales promotion on postpromotion brand preference: A meta-analysis. Journal of retailing, 82(3), 203-213.

Dichev, C., Dicheva, D., Angelova, G., \& Agre, G. (2015). From gamification to gameful design and gameful experience in learning. Cybernetics and Information Technologies, 14(4), 80-100.

Dichter, G. S., Smoski, M. J., Kampov-Polevoy, A. B., Gallop, R., \& Garbutt, J. C. (2010). Unipolar depression does not moderate responses to the Sweet Taste Test. Depression and anxiety, 27(9), 859-863. 
Ekman, J. B., \& Hake, M. K. (1990). Monitoring starvation risk: adjustments of body reserves in greenfinches (Carduelis chloris L.) during periods of unpredictable foraging success. BehavioralEcology, 1(1), 62-67.

Ellery, M. S., S. H.; Loba, P. (2005). Alcohol's Effects on Video Lottery Terminal (VLT) Play Among Probable Pathological and Non-Pathological Gamblers Journal of Gambling Studies, 21(3), 25.

Ellsberg, D. (1961). Risk, ambiguity, and the Savage axioms. The quarterly journalof economics, 643669.

Falk, J. L. (1961). Production of polydipsia in normal rats by an intermittent food schedule. Science, 133(3447), 195-196.

Falk, J. L. (1998). Drug abuse as an adjunctive behavior. Drug AlcoholDepend.

Falk, J. L., Samson, H. H., \& Winger, G. (1972). Behavioral maintenance of high concentration s of blood ethanol and physical dependence in the rat. Science, 177(4051), 811-813.

Falk, J. L., \& Tang, M. (1988). What schedule-induced polydipsia can tell us about alcoholism. Alcoholism: clinical and experimental research, 12(5), 577-585.

Faraji-Rad, A., \& Pham, M. T. (2017). Uncertainty increases the reliance on affect in decisions. Journal of Consumer Research, 44(1), 1-21.

Fields, S., Sabet, M., \& Reynolds, B. (2013). Dimensions of impulsive behavior in obese, overweight, and healthy-weight adolescents. Appetite, 70, 60-66.

Fiorillo, C. D., Tobler, P. N., \& Schultz, W. (2003). Discrete coding of reward probability and uncertainty by dopamine neurons. Science, 299(5614), 1898-1902.

Foulds, J., Veldheer, S., Yingst, J., Hrabovsky, S., Wilson, S. J., Nichols, T. T., \& Eissenbe rg, T. (2014). Development of a questionnaire for assessing dependence on electronic cigarettes among a large sample of ex-smoking E-cigarette users. Nicotine \& Tobacco Research, 17(2), 186-192.

Geiselman, P. J., Smith, C. F., Williamson, D. A., Champagne, C. M., Bray, G. A., \& Ryan, D. H. (1998). Perception of sweetness intensity determines women's hedonic and other perceptual responsiveness to chocolate food. Appetite, 31(1), 37-48.

Giacopassi, D., Stitt, B. G., \& Vandiver, M. (1998, Summer). An Analy sis of the Relationship of Alcohol to Casino Gambling Among College Students. J Gamb/Stud, 14(2), 135-149.

https://doi.org/416195 [pii] 
Goodwin, B. C., Browne, M., \& Rockloff, M. (2015). Measuring preference for su pernormal over natural rewards: A two-dimensional anticipatory pleasure scale. Evolutionary Psychology, 111.

Gottlieb, D. A. (2004). Acquisition with partial and continuous reinforcement in pigeon autoshaping. Animal Learning \& Behavior, 32(3), 321-334.

Griskevicius, V., Tybur, J. M., Delton, A. W., \& Robertson, T. E. (2011, Jun). The influence of mortality and socioeconomic status on risk and delayed rewards: a life history theory approach. $J$ Pers Soc Psychol, 100(6), 1015-1026. http://www.ncbi.nlm.nih.gov/pubmed/21299312

Heatherton, T., Kozlowski LK, Frecher RC, Fagerstrom KO. (1991). The Fagerstrom test for nicotine dependence: A revision of the Fagerstrom tolerance questionnaire. Brit J Addiction, 86, 119127.

Hendrickson, K. L., \& Rasmussen, E. B. (2013). Effects of mindful eating training on delay and probability discounting for food and money in obese and healthy-weight individuals. Behaviour research and therapy, 51(7), 399-409.

Hirschman, E. C., \& Holbrook, M. B. (1982). Hedonic consumption: emerging concepts, methods and propositions. Journal of marketing, 46(3), 92-101.

Hur, K., Choi, J. S., Zheng, M., Shen, J., \& Wrobel, B. (2018). Association of alterations in smell and taste with depression in older adults. Laryngoscope investigative otolaryngology, 3(2), 94-99.

Janowsky, D. S., Pucilowski, O., \& Buyinza, M. (2003). Preference for higher sucrose concentrations in cocaine abusing-dependent patients. Journal of Psychiatric Research, 37(1), 35-41.

Johnson, M. W., \& Bickel, W. K. (2002). Within-subject comparison of real and hypothetical money rewards in delay discounting. Journal of the experimental analysis of behavior, 77(2), 129146.

Kalra, A., \& Shi, M. (2010). Consumer value-maximizing sweepstakes and contests. Journal of Marketing Research, 47(2), 287-300.

Kampov-Polevoy, A. B., Alterman, A., Khalitov, E., \& Garbutt, J. C. (2006, Aug). Sweet preference predicts mood altering effect of and impaired control over eating sweet foods. Eat Behav, 7(3), 181-187. http://www.ncbi.nlm.nih.gov/pubmed/16843219

Kampov-Polevoy, A. B., Garbutt, J. C., \& Janowsky, D. (1997, Feb). Evidence of preference for a high concentration sucrose solution in alcoholic men. Am J Psychiatry, 154(2), 269-270. http://www.ncbi.nlm.nih.gov/pubmed/9016281 
Kampov-Polevoy, A. B., Garbutt, J. C., \& Khalitov, E. (2003). Family history of alcoholism and response to sweets. Alcoholism: clinical and experimental research, 27(11), 1743-1749.

Kim, J.-Y., Prescott, J., \& Kim, K.-O. (2014). Patterns of sweet liking in sucrose solutions and beverages. Food Quality and Preference, 36, 96-103.

Kocher, M. G., Krawczyk, M., \& van Winden, F. (2014). 'Let me dream on!'Anticipatory emotion s and preference for timing in lotteries. Journal of Economic Behavior \& Organization, 98, 29-40.

Koffarnus, M. N., \& Bickel, W. K. (2014, Jun). A 5-trial adjusting delay discounting task: accurate discount rates in less than one minute. Exp Clin Psychopharmacol, 22(3), 222-228. http://www.ncbi.nlm.nih.gov/pubmed/24708144

Konttinen, H., Van Strien, T., Männistö, S., Jousilahti, P., \& Haukkala, A. (2019). Depression, emotional eating and long-term weight changes: a population-based prospective study. International Journal of Behavioral Nutrition and Physical Activity, 16(1), 1-11.

Krahn, D., Grossman, J., Henk, H., Mussey, M., Crosby, R., \& Gosnell, B. (2006). Sweet intake, sweetliking, urges to eat, and weight change: relationship to alcohol dependence and abstinence. Addictive behaviors, 31(4), 622-631.

Kranzler, H. R., Sandstrom, K. A., \& Van Kirk, J. (2001). Sweet taste preference as a risk factor for alcohol dependence. American Journal of Psychiatry, 158(5), 813-815.

Kurtz, J. L., Wilson, T. D., \& Gilbert, D. T. (2007). Quantity versus uncertainty: When winning one prize is better than winning two. Journal of Experimental Social Psychology, 43(6), 979-985.

Kyngdon, A., Dickerson M. (1999). An experimental study of the effect of prior alcohol consumption on a simulated gambling activity. Addiction, 94, 697-707.

Ladouceur, R., Sévigny, S., Blaszczynski, A., O'Connor, K., \& Lavoie, M. E. (2003). Video lottery: Winning expectancies and arousal. Addiction, 98(6), 733-738.

Lagorio, C. H., \& Madden, G. J. (2005). Delay discounting of real and hypothetical rewards III: Steadystate assessments, forced-choice trials, and all real rewards. Behavioural Processes, 69(2), 173-187.

Lawrence, N. S., Verbruggen, F., Morrison, S., Adams, R. C., \& Chambers, C. D. (2015). Stopping to food can reduce intake. Effects of stimulus-specificity and individual differences in dietary restraint. Appetite, 85, 91-103.

Lenoir, M., Serre, F., Cantin, L., \& Ahmed, S. H. (2007). Intense sweetness surpasses cocaine reward. PLoSOne, 2(8), e698. 
Levin, I. P., Schneider, S. L., \& Gaeth, G. J. (1998). All Frames Are Not Created Equal: A Typology and Critical Analysis of Framing Effects. Organizational Behavior and Human Decision Processes, 76(2), 149-188. http://www.sciencedirect.com/science/article/B6WP2-45M2Y854/1/fbdfd421936f41492f023b09a5dd7643

Levine, A. S., Kotz, C. M., \& Gosnell, B. A. (2003). Sugars: hedonic aspects, neuroregulation, and energy balance. The American journal of clinical nutrition, 78(4), 834S-842S.

Li, W., Mills, D., \& Nower, L. (2019). The relationship of loot box purchases to problem video gaming and problem gambling. Addictive behaviors, 97, 27-34.

Lloyd, J., Doll, H., Hawton, K., Dutton, W. H., Geddes, J. R., Goodwin, G. M., \& Rogers, R. D. (2010). How psychological symptoms relate to different motivations for gambling: an online study of internet gamblers. Biological psychiatry, 68(8), 733-740.

Loewenstein, G., \& Elster, J. (1992). Choice over time. Russell Sage Foundation.

Lovallo, D., \& Kahneman, D. (2000). Living with uncertainty: Attractiveness and resolution timing. Journal of BehavioralDecision Making, 13(2), 179-190.

Lowenstein, G., Hsce, C., \& Weber, E. (2001). Risk all feelings. PsychologicalBulletin, 127, Z67-Z86.

Madden, G. J., Begotka, A. M., Raiff, B. R., \& Kastern, L. L. (2003). Delay discounting of real and hypothetical rewards. Experimental and Clinical Psychopharmacology, 11(2), 139.

Madden, G. J., Petry, N. M., \& Johnson, P. S. (2009). Pathological gamblers discount probabilistic rewards less steeply than matched controls. Experimental and Clinical Psychopharmacology, 17(5), 283.

Manwaring, J. L., Green, L., Myerson, J., Strube, M. J., \& Wilfley, D. E. (2011). Discounting of various types of rewards by women with and without binge eating disorder: evidence for general rather than specific differences. The Psychological Record, 61(4), 561-582.

Matusiewicz, A. K., Carter, A. E., Landes, R. D., \& Yi, R. (2013). Statistical equivalence and test-retest reliability of delay and probability discounting using real and hypothetical rewards. Behavioural Processes, 100, 116-122.

Meyer, G., Hauffa, B. P., Schedlowski, M., Pawlak, C., Stadler, M. A., \& Exton, M. S. (2000). Casino gambling increases heart rate and salivary cortisol in regular gamblers. Biological psychiatry, 48(9), 948-953.

Meyer, G., Schwertfeger, J., Exton, M. S., Janssen, O. E., Knapp, W., Stadler, M. A., Schedlowski, M., \& Krüger, T. H. (2004). Neuroendocrine response to casino gambling in problem gamblers. Psychoneuroendocrinology, 29(10), 1272-1280. 
Milkman, K. L. (2012). Unsure what the future will bring? You may overindulge: Uncertainty increases the appeal of wants over shoulds. Organizational Behavior and Human Decision Processes, 119(2), 163-176.

Moskowitz, H. R. (1971). The sweetness and pleasantness of sugars. The American journalof psychology, 387-405.

Moskowitz, H. R., Kluter, R. A., Westerling, J., \& Jacobs, H. L. (1974). Sugar sweetness and pleasantness: evidence for different psychological laws. Science, 184(4136), 583-585.

Navarro, D. J., Newell, B. R., \& Schulze, C. (2016). Learning and choosing in an uncertain world: An investigation of the explore-exploit dilemma in static and dynamic environments. Cognitive psychology, 85, 43-77.

Nederkoorn, C., Houben, K., Hofmann, W., Roefs, A., \& Jansen, A. (2010). Control yourself or just eat what you like? Weight gain over a year is predicted by an interactive effect of response inhibition and implicit preference for snack foods. Health Psychology, 29(4), 389.

Nielsen, R. K. L., \& Grabarczyk, P. (2019). Are Loot Boxes Gambling? Random reward mechanisms in video games. Transactions of the Digital Games Research Association, 4(3).

Noel, C., \& Dando, R. (2015). The effect of emotional state on taste perception. Appetite, 95, 89-95.

O'Curry, S., \& Strahilevitz, M. (2001). Probability and mode of acquisition effects on choices between hedonic and utilitarian options. Marketing Letters, 12(1), 37-49.

Odum, A. L. (2011). Delay discounting: I'm a K, you're a K. ExperimentalAnalysis of Behaviour, 96, 427-439.

Odum, A. L., Baumann, A. A., \& Rimington, D. D. (2006). Discounting of delayed hypothetical money and food: Effects of amount. Behavioural Processes, 73(3), 278-284.

Orford, J. (2000). Conceptualizing addiction. Addiction as excessive appetite.

Pangborn, R. M. (1970). Individual variation in affective responses to taste stimuli. Psychonomic Science, 21(2), 125-126.

Pearce, J., Kaye, H., \& Hall, G. (1982). Predictive accuracy and stimulus associability: Development of a model for Pavlovian learning. Quantitative analyses of behavior, 3, 241-256.

Pelizza, L., \& Ferrari, A. (2009). Anhedonia in schizophrenia and major depression: state or trait? Annals of General Psychiatry, 8(1), 22. 
Peters, J., \& Buchel, C. (2010, Apr 15). Episodic future thinking reduces reward delay discounting through an enhancement of prefrontal-mediotemporal interactions. Neuron, 66(1), 138-148. http://www.ncbi.nIm.nih.gov/entrez/query.fcgi?cmd=Retrieve\&db=PubMed\&dopt=Citation \&list_uids $=20399735$

Petry, N. (2001). Delay discounting of money and alcohol in actively using alcoholics, currently abstinent alcoholics, and controls. Psychopharmacol, 154, 243-250.

Pfaffmann, C. (1980). Wundt's schema of sensory affect in the light of research on gustatory preferences. Psychological research, 42(1-2), 165-174.

Platte, P., Herbert, C., Pauli, P., \& Breslin, P. A. (2013). Oral perceptions of fat and taste stimuli are modulated by affect and mood induction. PLoS One, 8(6), e65006.

Potts, A. J., Bennett, P. J., Kennedy, S. H., \& Vaccarino, F. J. (1997). Depressive symptoms and alterations in sucrose taste perception: cognitive bias or a true change in sensitivity? Canadian Journal of Experimental Psychology/Revue canadienne de psychologie expérimentale, 51(1), 57.

Rasmussen, E. B., Lawyer, S. R., \& Reilly, W. (2010). Percent body fat is related to delay and probability discounting for food in humans. Behavioural Processes, 83(1), 23-30.

Rauwolf, P., Millard, S., Wong, N., Witt, A., Davies, T. J., Cahill, A., Madden, G. J., Parkinson, J. A., \& Rogers, R. D. (2020, August 28). Data for: "Just not knowing" can make life sweeter (and saltier): Reward uncertainty alters the sensory experience and consumption of palatable food and drinks. Retrieved from osf.io/qdncm. https://osf.io/qdncm/

Reynolds, B., Richards, J. B., Horn, K., \& Karraker, K. (2004, Jan 30). Delay discounting and probability discounting as related to cigarette smoking status in adults. Behav Processes, 65(1), 35-42. http://www.ncbi.nIm.nih.gov/entrez/query.fcgi?cmd=Retrieve\&db=PubMed\&dopt=Citation \&list_uids $=14744545$

Riskey, D. R., Parducci, A., \& Beauchamp, G. K. (1979). Effects of context in judgments of sweetness and pleasantness. Perception \& Psychophysics, 26(3), 171-176.

Robinson, E., Haynes, A., Hardman, C. A., Kemps, E., Higgs, S., \& Jones, A. (2017). The bogus taste test: Validity as a measure of laboratory food intake. Appetite, 116, 223-231.

Robinson, E., Kersbergen, I., Brunstrom, J. M., \& Field, M. (2014). I'm watching you. Awareness that food consumption is being monitored is a demand characteristic in eating-behaviour experiments. Appetite, 83, 19-25. 
Robinson, M. J., Anselme, P., Suchomel, K., \& Berridge, K. C. (2015). Amphetamine-induced sensitization and reward uncertainty similarly enhance incentive salience for conditioned cues. Behavioralneuroscience, 129(4), 502.

Roper, T. (1981). What is meant by the term "schedule-induced," and how general is schedule induction? Animal Learning \& Behavior, 9(4), 433-440.

Ruan, B., Hsee, C. K., \& Lu, Z. Y. (2018). The teasing effect: An underappreciated benefit of creating and resolving an uncertainty. Journal of Marketing Research, 55(4), 556-570.

Rung, J. M., \& Madden, G. J. (2018). Experimental reductions of delay discounting and impulsive choice: A systematic review and meta-analysis. Journal of experimental psychology: general, 147(9), 1349.

Samson, H. H., \& Falk, J. L. (1974). Schedule-induced ethanol polydipsia: Enhancement by saccharin. Pharmacology Biochemistry and Behavior, 2(6), 835-838.

Saunders, J. B., Aasland, O. G., Babor, T. F., de la Fuente, J. R., \& Grant, M. (1993). Development of the Alcohol Use Disorders Identification Test (AUDIT): WHO Collaborative Project on Early Detection of Persons with Harmful Alcohol Consumption--II. Addiction, 88(6), 791-804.

Schultz, W., Preuschoff, K., Camerer, C., Hsu, M., Fiorillo, C. D., Tobler, P. N., \& Bossaerts, P. (2008, Dec 12). Explicit neural signals reflecting reward uncertainty. Philos Trans $R$ Soc Lond B Biol Sci, 363(1511), 3801-3811. http://www.ncbi.nlm.nih.gov/entrez/query.fcgi?cmd=Retrieve\&db=PubMed\&dopt=Citation \&list uids $=18829433$

Scinska, A., Sienkiewicz-Jarosz, H., Kuran, W., Ryglewicz, D., Rogowski, A., Wrobel, E., Korkosz, A., Kukwa, A., Kostowski, W., \& Bienkowski, P. (2004). Depressive symptoms and taste reactivity in humans. PhysiolBehav, 82(5), 899-904.

Shen, L., Hsee, C. K., \& Talloen, J. H. (2019). The Fun and Function of Uncertainty: Uncertain Incentives Reinforce Repetition Decisions. Journal of Consumer Research, 46(1), 69-81.

Slovic, P., Peters, E., Finucane, M. L., \& MacGregor, D. G. (2005). Affect, risk, and decision making. Health Psychology, 24(4S), S35.

Snider, S. E., LaConte, S. M., \& Bickel, W. K. (2016). Episodic fut ure thinking: Expansion of the temporal window in individuals with alcohol dependence. Alcoholism: clinical and experimental research, 40(7), 1558-1566.

Steiner, J. E., Lidar-Lifschitz, D., \& Perl, E. (1993). Taste and odor: reactivity in depressive disorders, a multidisciplinary approach. Perceptualand motor skills, 77(3_suppl), 1331-1346. 
Steiner, J. E., Rosenthal-Zifroni, A., \& Edelstein, E. L. (1969). Taste perception in depressive illness. Israel Annals of Psychiatry \& Related Disciplines, 7, 223-232.

Stevens, T., Brevers, D., Chambers, C. D., Lavric, A., McLaren, I. P., Mertens, M., Noël, X., \& Verbruggen, F. (2015). How does response inhibition influence decision making when gambling? Journal of Experimental Psychology: Applied, 21(1), 15.

Stevenson, B. L., Dvorak, R. D., Kramer, M. P., Peterson, R. S., Dunn, M. E., Leary, A. V., \& Pinto, D. (2019). Within-and between-person associations from mood to alcohol consequences: The mediating role of enhancement and coping drinking motives. Journal of abnormal psychology, 128(8), 813.

Stewart, S. H., Collins, P., Blackburn, J. R., Ellery, M., \& Klein, R. M. (2005). Heart rate increase to alcohol administration and video lottery terminal (VLT) play among regular VLT players. Psychology of Addictive Behaviors, 19(1), 94.

Stojek, M. M., \& MacKillop, J. (2017). Relative reinforcing value of food and delayed reward discounting in obesity and disordered eating: a systematic review. Clinical psychology review, 55, 1-11.

Sztainert, T., Hay, R., Wohl, M. J., \& Abizaid, A. (2018). Hungry to gamble? Ghrelin as a predictor of persistent gambling in the face of loss. Biological psychology, 139, 115-123.

Tan, S.-Y., \& Tucker, R. M. (2019). Sweet taste as a predictor of dietary intake: A systematic review. Nutrients, 11(1), 94.

Tibboel, H., De Houwer, J., \& Van Bockstaele, B. (2015). Implicit measures of "wanting" and "liking" in humans. Neuroscience \& Biobehavioral Reviews, 57, 350-364.

Tobias-Webb, J., Griggs, R. L., Kaufman, N., \& Clark, L. (2019). Role Reversal: The Influence of Slot Machine Gambling on Subsequent Alcohol Consumption. Journal of Gambling Studies, 35(1), 321-337.

Topp, C. W., Østergaard, S. D., Søndergaard, S., \& Bech, P. (2015). The WHO-5 Well-Being Index: a systematic review of the literature. Psychotherapy and psychosomatics, 84(3), 167-176.

Tversky, A., \& Edwards, W. (1966). Information versus reward in binary choices. Journal of Experimental Psychology, 71(5), 680.

Tversky, A., \& Kahneman, D. (1981, Jan 30). The framing of decisions and the psychology of choice. Science, 211(4481), 453-458. http://www.ncbi.nlm.nih.gov/entrez/query.fcgi? cmd=Retrieve\&db=PubMed\&dopt=Citation \&list uids $=7455683$ 
4

van Opstal, A., Hafkemeijer, A., van den Berg-Huysmans, A., Hoeksma, M., Blonk, C., Pijl, H., Rombouts, S., \& van der Grond, J. (2020). Brain activity and connectivity changes in response to glucose ingestion. Nutritionalneuroscience, 23(2), 110-117.

van Strien, T., Konttinen, H., Homberg, J. R., Engels, R. C., \& Winkens, L. H. (2016). Emotional eating as a mediator between depression and weight gain. Appetite, 100, 216-224.

Verbruggen, F., Adams, R., \& Chambers, C. D. (2012, Jul 1). Proactive motor control reduces monetary risk taking in gambling [Research Support, Non-U.S. Gov't]. PsycholSci, 23(7), 805815. http://www.ncbi.nlm.nih.gov/pubmed/22692336

Wang, Q., \& Spence, C. (2018). "A sweet smile": the modulatory role of emotion in how extrinsic factors influence taste evaluation. Cognition and Emotion, 32(5), 1052-1061.

Ward, A. F. (2013). Supernormal: How the Internet is changing our memories and our minds. Psychologicallnquiry, 24(4), 341-348.

Wardle, H., Reith, G., Langham, E., \& Rogers, R. D. (2019). Gambling and public health: we need policy action to prevent harm. BMJ, 365, I1807.

Watson, D., Clark, L. A., \& Tellegen, A. (1988, Jun). Development and validation of brief measures of positive and negative affect: the PANAS scales. J Pers Soc Psychol, 54(6), 1063-1070.

Weafer, J., Burkhardt, A., \& de Wit, H. (2014). Sweet taste liking is associated with impulsive behaviors in humans. Front Behav Neurosci, 8, 228. https://doi.org/10.3389/fnbeh.2014.00228

Whitchurch, E. R., Wilson, T. D., \& Gilbert, D. T. (2011). “He Loves Me, He Loves Me Not..." Uncertainty Can Increase Romantic Attraction. PsycholSci, 22(2), 172-175.

Wilcox, C., \& Woodside, A. G. (2012). The high stakes of sweepstakes: Too much of a good thing can demotivate digital consumers. Journal of Advertising Research, 52(2), 167-179.

Wilson, J. F., \& Cantor, M. B. (1987). AN ANIMALMODEL OF EXCESSIVE EATING: SCHEDULE-INDUCED HYPERPHAGIA IN FOOD-SATIATED RATS. Journal of the experimental analysis of behavior, 47(3), 335-346.

Wilson, T. D., Centerbar, D. B., Kermer, D. A., \& Gilbert, D. T. (2005). The pleasures of uncertainty: prolonging positive moods in ways people do not anticipate. Journalof personality and social psychology, 88(1), 5.

Worhunsky, P. D., \& Rogers, R. D. (2018). An initial investigation of individual rate-of-play preferences and associations with EGM gambling behavior. Journal of Gambling Studies, 34(4), 1067-1083. 
2 Zack, M., Featherstone, R. E., Mathewson, S., \& Fletcher, P. J. (2014). Chronic exposure to a gambling-like schedule of reward predictive stimuli can promote sensitization to amphetamine in rats. Frontiers in behavioral neuroscience, 8, 36.

Zandstra, E. H., de Graaf, C., van Trijp, H. C., \& van Staveren, W. A. (1999). Laboratory hedonic ratings as predictors of consumption. Food Quality and Preference, 10(4-5), 411-418.

8

Zauberman, G., Kim, B. K., Malkoc, S. A., \& Bettman, J. R. (2009). Discounting time and time discounting: Subjective time perception and intertemporal preferences. Journal of Marketing Research, 46(4), 543-556.

Zeeb, F. D., Li, Z., Fisher, D. C., Zack, M. H., \& Fletcher, P. J. (2017). Uncertainty exposure causes behavioural sensitization and increases risky decision-making in male rats: toward modelling gambling disorder. Journal of psychiatry \& neuroscience:JPN, 42(6), 404.

Zendle, D., Meyer, R., Cairns, P., Waters, S., \& Ballou, N. (2020). The prevalence of loot boxes in mobile and desktop games. Addiction. 